\title{
LA DIMENSIÓN LEGAL DE LA INTERPRETACIÓN CONSTITUCIONAL*
}

\section{THE LEGALISTIC SCOPE OF CONSTITUTIONAL INTERPRETATION}

\author{
Luis Alejandro Silva IrarráZaval**
}

\begin{abstract}
RESUMEN: En este trabajo se discute una de las premisas de la supremacía constitucional, que es la unidireccionalidad del proceso de interpretación comprendido en el control de constitucionalidad de la ley. Parece ampliamente aceptado que el juicio de conformidad de la ley consiste y se agota en interpretar su texto a la luz de la Constitución, y que la ley no tiene influencia alguna en la interpretación de la Constitución. Contra la presunción de que la ley no incide en la interpretación de la Constitución, este artículo ofrece una serie de razones que muestran la influencia que tiene la ley en la determinación del sentido y alcance de la norma constitucional. Puede decirse que el control de constitucionalidad de la ley descansa en una dinámica hermenéutica bidireccional: ley y Constitución se iluminan recíprocamente en el proceso de precisar el significado de cada una. El foco de esta investigación está puesto en el aspecto de dicho proceso que ha sido más descuidado por la doctrina, cual es la repercusión de la ley en la interpretación de la Constitución.
\end{abstract}

Palabras clave: Interpretación constitucional; supremacía constitucional; Tribunal Constitucional

ABSTRACT: This paper argues against one of the premises on which relies the supremacy of the Constitution. This premise consists on the one-way process of interpretation comprehended in judicial review. In fact, it seems broadly accepted that the judgment of constitutionality is resolved only by interpreting the ordinary law according to the Constitution. We object that presumption. Instead, this article provides some reasons which proved the influence of the ordinary law on the process of interpreting the Constitution. In this sense, it could be said that judicial review is grounded on a bidirectional process of interpretation, because ordinary law affects the understanding of the Constitution and vice versa. The paper is focused in the abandoned aspect of that bidirectional process, which is the influence of the ordinary law on the interpretation of the Constitution.

Key words: Interpretation of the Constitution; supremacy of the Constitution; Constitutional Court

\section{INTRODUCCIÓN}

La Constitución es el parámetro del control de constitucionalidad de la ley. Esto es doctrina común y significa que la ley debe interpretarse a la luz de la Constitución cuando se pretende verificar si es conforme con ella o no. Menos común es la doctrina que reco-

\footnotetext{
* Este trabajo se enmarca en el Proyecto Fondecyt Iniciación № 11110128, en el cual soy el Investigador Responsable. Agradezco al tesista Claudio Ereche por la ayuda que su trabajo supuso para esta investigación.

** Profesor de Derecho Constitucional de la Facultad de Derecho de la Universidad de los Andes, Av. Mons. Álvaro del Portillo 12.455, Las Condes, Santiago de Chile. Doctor en Derecho. Mail: 1silva@uandes.cl.
} 
noce la necesidad de interpretar la Constitución en el acto mismo que sirve como canon de interpretación de la ley. Pero lo que resulta prácticamente una rareza es afirmar que la Constitución es interpretada según la ley. Y esto último es lo que se postula en este trabajo.

El control de constitucionalidad de la ley consiste en la actividad de juzgar si la ley es conforme con la Constitución. Cuando la interpretación de la ley supera esta prueba (v.gr. es conforme con la Constitución), entonces es constitucional. Es obvio que la ley debe ser interpretada para determinar si es constitucional, y que el canon de interpretación es la Constitución. Sin embargo, la Constitución no es una regla cuyo significado sea claro para el que la aplica; la Constitución también necesita ser interpretada.

Sobre la interpretación de la Constitución se ha escrito mucho. Parte importante de todo ese material se aboca a las fuentes y reglas de la interpretación constitucional. Es este un punto especialmente delicado desde cierta perspectiva, porque está en juego una característica esencial de la Constitución, que es la supremacía jerárquica. En efecto, lo que se diga de las fuentes y reglas de interpretación de la Constitución es crítico desde la perspectiva de la supremacía constitucional, porque la garantía de su posición en la cúspide del ordenamiento dependerá de que su interpretación no esté sujeta a ningún canon o procedimiento de jerarquía inferior. De aquí que, entre los muchos matices que hay respecto de las fuentes y reglas de la interpretación de la Constitución, exista una coincidencia por lo menos. Y esta coincidencia es que la ley no puede ser ni fuente ni regla de interpretación de la Constitución.

La ley no podría servir como criterio de interpretación de la Constitución, por ser jerárquicamente inferior a la Constitución. Si se aceptara lo contrario, se estaría subvirtiendo una parte fundamental de la estructura que sostiene al ordenamiento jurídico. En otras palabras, sería incompatible con la supremacía constitucional sostener que la ley es útil para determinar el sentido de la Constitución en el mismo acto en que la Constitución sirve para interpretar la ley. Sin embargo, hay buenas razones para sostener precisamente eso. Y estas razones están respaldadas por la jurisprudencia del Tribunal Constitucional.

La jurisprudencia del Tribunal Constitucional enseña que la ley es un elemento en muchos casos decisivo para interpretar la Constitución. Esta conclusión es consistente con varios motivos de distinta naturaleza (política, hermenéutica, jurídica) que conducen al mismo resultado: la interpretación de la Constitución es un proceso que normalmente no prescinde de la ley. Este trabajo se orienta a demostrar esta conclusión.

El artículo se divide, fundamentalmente, en tres partes. En la primera de ellas se caracteriza el principio de interpretación conforme con la Constitución según la doctrina dominante (apartados II y III). En la segunda parte se ofrece un repertorio de sentencias del Tribunal Constitucional en que no se refleja el principio de interpretación conforme según su formulación doctrinal dominante. En la jurisprudencia seleccionada, en cambio, aparece que la ley tiene una función decisiva en la determinación del sentido de la Constitución (apartado IV). En la tercera parte se sistematizan los motivos que explican lo que antes se ha constatado en la jurisprudencia del Tribunal Constitucional (apartado V). 


\section{LA INTERPRETACIÓN CONFORME CON LA CONSTITUCIÓN}

Se impone, en primer lugar, una caracterización del principio de interpretación conforme con la Constitución, con el propósito de perfilar el objeto de esta investigación. Estimo que esta finalidad queda cumplida destacando, en primer lugar, la relación que el principio de interpretación conforme tiene con la supremacía constitucional y, en segundo lugar, ofreciendo una clasificación del mismo principio de acuerdo a los distintos sentidos en que puede entenderse.

\section{A. INTERPRETACIÓN CONFORME Y SUPREMACÍA CONSTITUCIONAL}

La supremacía constitucional es un principio que, desde la segunda mitad del siglo $\mathrm{XX}$, se traduce generalmente en una eficacia directa e inmediata de la Constitución como norma jurídica aplicable por los jueces. Esta eficacia se manifiesta a través de varias formas; una de ellas es la obligación de interpretar todos los elementos normativos integrantes del ordenamiento jurídico conforme con la Constitución.

La posición que la Constitución ocupa en el orden jerárquico del ordenamiento jurídico, implica la interpretación conforme con ella de todo el resto de las normas. "La supremacía de la Constitución (...) y su carácter central (...) en la validez del ordenamiento (...) obligan a interpretar este en cualquier momento de su aplicación (...) en el sentido que resulta de los principios y deberes constitucionales (...) Este principio es una consecuencia derivada del carácter normativo de la Constitución y de su rango supremo y está reconocido en los sistemas que hacen de ese carácter un postulado básico" ${ }^{1}$. Este es, por otra parte, el sentido en que se ha interpretado el artículo 6 inc. $2^{\circ}$ de la Constitución chilena.

La conexión del principio de interpretación conforme con el de la supremacía constitucional, puede ilustrarse con los diferentes trabajos del profesor Humberto Nogueira. En su libro Dogmática Constitucional explica que la Constitución tiene eficacia normativa directa, lo cual implica para todos los aplicadores del Derecho, y en particular para los jueces, el deber de examinar "si las demás normas jurídicas respetan la Constitución, tanto material como formalmente", así como el deber de "interpretar todo el ordenamiento jurídico conforme a la Constitución" ${ }^{2}$. En un trabajo posterior extrae las consecuencias de la supremacía constitucional en cuanto postulado hermenéutico: "La Constitución es el parámetro interpretativo obligatorio de todo el ordenamiento jurídico del Estado" ${ }^{\text {. De la }}$ naturaleza normativa de la Constitución emana directamente el principio de interpretación conforme, que es también un postulado hermenéutico: "Este postulado es una consecuencia directa del carácter de norma suprema, de norma unitaria y de la fuerza normativa de la

\footnotetext{
1 García de Enterría (1983), p. 95.

2 Nogueira (1997), p. 21.

3 Nogueira (2009), p. 157.
} 
Constitución”“. En definitiva, se entiende que esta función hermenéutica emana de su valor supremo y normativo y, al mismo tiempo, lo fortaleces.

Lo que me interesa destacar de la vinculación entre el principio de interpretación conforme y la naturaleza suprema y normativa de la Constitución, es la concepción de la supremacía que subyace a esa vinculación. Esta precisión es necesaria porque la supremacía no es un concepto funcionalmente unívoco; su significado puede interpretarse de modo que se le atribuyan consecuencias diferentes. La idea de que la supremacía implica para todos los operadores del Derecho la obligación de interpretar el ordenamiento conforme con la Constitución, corresponde a una de las posibles formas de entender la supremacía. Una variante, por cierto ampliamente aceptada hoy, que extrema las potencialidades de la Constitución entendida como norma jurídica, pero que en ningún caso puede entenderse que agota el significado de la supremacía. De hecho, en la conclusión de este trabajo se relativizan los postulados en que se sostiene esta forma de entender la supremacía constitucional.

\section{B. Clasificación de la interpretación CONFORME}

El principio de interpretación conforme no tiene un significado unívoco: con el mismo nombre se expresan realidades parcialmente distintas. La interpretación conforme puede entenderse como un resultado y como un deber. Y en cuanto deber, puede entenderse en un sentido amplio y en otro restringido.

\section{Interpretación conforme como resultado}

Como resultado, la interpretación conforme es sinónimo de constitucionalidad, en cuanto cualidad probada $-\mathrm{y}$ no presumida- de una norma. Es el efecto que confirma la condición básica de validez de una norma, que es el ser conforme con la Constitución. En este sentido se dice que una norma, después de haber superado el control de constitucionalidad, es constitucional o conforme con la Constitución.

\section{Interpretación conforme como deber}

Como deber significa la necesidad de interpretar cualquier norma conforme con la Constitución, como condición de validez de dicha norma. El fundamento normativo de este deber es el artículo 6 inc. 10 de la Constitución: "Los órganos del Estado deben someter su acción a la Constitución y a las normas dictadas conforme a ella”. La validez de las normas está condicionada a su conformidad con la Constitución. Esto implica para cualquier órgano del Estado que deba aplicar una norma, verificar antes si cumple con esa condición ${ }^{6}$. Esta obligación descansa en el principio de jerarquía normativa y opera como un mecanismo de aseguramiento de la supremacía de la Constitución. Podría decirse que

\footnotetext{
4 Nogueira (2009), p. 168. Aldunate (2009), p. 446, también muestra la asociación entre fuerza normativa de la Constitución y la obligación de interpretación conforme.

5 Nogueira (2009), p. 158. Esta es doctrina pacífica. Por citar algunos: (Verdugo et al.; 1994, pp. 131 y 132; Soto Kloss; 1996, pp. 68-69; Silva; 1997, p. 123).

${ }^{6}$ Esto no supone necesariamente, en cambio, que si el órgano detecta una incompatibilidad esté habilitado para dejar de aplicar la norma estimada inconstitucional. En contra (SоTO KLOss; 1996, p. 37 nota al pie n. 29; Ríos; 2002).
} 
el principio de interpretación conforme es la expresión de la supremacía constitucional en el acto de interpretar la norma infraconstitucional. En este sentido, su alcance se extiende a todos los casos en que se aplica una norma, porque la norma solo puede aplicarse si es conforme con la Constitución. Aquí conviene puntualizar que el principio así entendido no es exclusivo de la función de control de constitucionalidad de la ley, aunque al mismo tiempo es preciso reconocer que su aplicación conlleva implícita y necesariamente un juicio de constitucionalidad de la ley ${ }^{7}$.

De modo ordinario se entiende la interpretación conforme como un deber dirigido al intérprete del Derecho. Y este deber ordena que el Derecho aplicado se interprete conforme con la Constitución. El fundamento de este deber es el carácter supremo y normativo de la Constitución, que se traduce en un efecto vinculante directo e inmediato para todos. Sin embargo, el alcance de este deber es ambiguo, porque la obligación del intérprete puede entenderse en dos sentidos. El primero consiste en que no puede aplicarse una norma que sea incompatible con la Constitución (lo que de paso permite presumir que las normas que se aplican son conformes con la Constitución). El segundo sentido consiste en que el intérprete debe esforzarse por hallar en las normas un sentido que sea conforme con la Constitución. La diferencia es sutil, pero existe. En el primer caso puede hablarse de un sentido amplio del deber, y en el segundo caso de un sentido restringido.

\section{a) Como deber en sentido amplio}

En un sentido amplio, el deber de interpretar la ley conforme con la Constitución es el que se ha expuesto más arriba, en la formulación: consiste en la obligación de interpretar todas las normas de acuerdo con los contenidos de la Constitución. La Constitución es el parámetro que condiciona la aplicación de cualquier otro precepto. De este modo, con el cumplimiento de este deber, se garantiza la supremacía constitucional. Este es el sentido de las palabras de Soto Kloss: "Jamás ha de olvidarse que es la Constitución la que sujeta todo el ordenamiento, le da sustento y soporte a todo él en la medida que este se adecua y conforma con ella"s.

La amplitud del principio así entendido se compensa con su influjo virtual, porque en la práctica se procede sobre la base de que la ley es conforme con la Constitución. ${ }^{9}$ Lo normal es que la conformidad de la ley con la Constitución no sea revisada; la excepción la constituyen los casos en que resulta conveniente o necesario efectuar tal revisión. La inexistencia de un examen explícito de conformidad de la ley con la Constitución no significa que el principio haya dejado de aplicarse, sino que ha sido aplicado de manera virtual.

\footnotetext{
7 Se entiende que la función de controlar la constitucionalidad de la ley implica el poder para evitar la eficacia de la norma infractora de la Constitución (no importa ahora la forma: si inaplicabilidad, inconstitucionalidad, nulidad, derogación); este poder es el que diferencia la atribución constitucional de control de la ley, del deber ineludible de cualquier órgano que aplica la ley de verificar que ella es conforme con la Constitución. Esta diferencia está reconocida por NogUeira (2009), p. 173: "la interpretación conforme a la Constitución puede ser desarrollada en nuestro país por todos los órganos de jurisdicción ordinaria o especial, pero no todos ellos desarrollan control de constitucionalidad”. En el mismo sentido Bordalí (2009).

8 Soto Kloss (1996), p. 68.

9 Una expresión de esto es la doctrina de la presunción de constitucionalidad de las leyes en la jurisprudencia del Tribunal Constitucional. Por todas, Izquierdo Artigas (2007), cons. $6^{\circ}$.
} 


\section{b) Como deber en sentido restringido}

En el marco de la versión amplia del principio, es posible reconocer la existencia de una versión de alcance más acotado. Esta versión consiste en la identificación del principio con una actitud de cortesía o deferencia del órgano de control hacia el legislador. Esta actitud se traduce en preferir aquella interpretación de la ley que se conforme con la Constitución, cuando caben otras que resultan incompatibles con ella. Se llaman interpretativas las sentencias que concretan esta actitud de deferencia ${ }^{10}$.

Típicamente, las referencias al principio de interpretación conforme que pueden hallarse en la doctrina y en la jurisprudencia, identifican el principio con su acepción restringida. Aunque la fórmula no es siempre idéntica, la inspiración es la misma: evitar las declaraciones de inconstitucionalidad, ofreciendo una interpretación de la ley que sea conforme con la Constitución. La razón que normalmente se ofrece para justificar este criterio es la deferencia que los órganos del Estado se deben entre sí, que para los órganos de control jurisdiccional se traduce en preferir la interpretación que salve a la ley de una declaración de inconstitucionalidad.

Es importante destacar que esta versión del principio es una especificación de la versión amplia, que se caracteriza por su énfasis en los elementos políticos de la función de control de constitucionalidad de la ley ${ }^{11}$. El sentido restringido del deber de interpretación conforme oscurece la función que cumple la Constitución como canon de interpretación, porque no se fija tanto en cómo la Constitución es utilizada por el intérprete para desentrañar el sentido y alcance de la ley, sino más en cómo la Constitución lleva a preferir una interpretación por sobre otra (aunque las dos satisfagan los estándares de una interpretación formalmente correcta). Por esta razón, el presente trabajo se enfoca en el sentido amplio del principio.

\section{LA INTERPRETACIÓN CONFORME ES UNIDIRECCIONAL}

En este apartado se aborda un aspecto del principio de interpretación conforme que, en el marco de la tesis de este trabajo, resulta problemático desde una perspectiva hermenéutica. El problema consiste en determinar si la ley sirve como criterio de interpretación de la Constitución, cuando el Tribunal Constitucional controla la constitucionalidad de la ley. Porque, si bien es la ley el objeto del control de constitucionalidad y, por lo tanto, es la ley la que debe ser interpretada a la luz de la Constitución, es necesario en esta operación interpretar la Constitución también. Pero la Constitución, ¿̇conforme a qué criterios se interpretará? Aunque la respuesta a esta pregunta pueda variar más o menos, en un punto sí

\footnotetext{
10 (Ribera, 1989; Valenzuela, 2006). Una exhaustiva taxonomía de estas sentencias en el derecho comparado en DÍAZ (2011).

11 Es común encontrar asociado el principio de interpretación conforme con otros principios o máximas, como son la deferencia razonada, la presunción de constitucionalidad de la ley, la separación de los poderes y la tolerancia de la ley cuando de su inconstitucionalidad se siguen efectos peores. Esta asociación es importante para explicar la diferencia entre el sentido amplio y el sentido restringido del principio. Dando por sentado que la deferencia razonada, la presunción de constitucionalidad, la separación de los poderes y la tolerancia del mal menor son en sí mismas, máximas con un contenido mucho más político que jurídico, se puede inferir que la acepción restringida del principio es más política que la acepción amplia.
} 
hay consenso: la Constitución no puede ser interpretada conforme con la ley. En este sentido puede decirse que la dinámica hermenéutica inherente al control de constitucionalidad de la ley es unidireccional, es decir, va de la Constitución a la ley, pero no a la inversa. En el presente apartado se ofrece un análisis de las premisas de dicha conclusión.

\section{A. LA INTERPRETACIÓN DE LA LEY}

La independencia que hay entre la aplicación de la ley y de la Constitución es lo que posibilita que la Constitución sirva como canon de interpretación de la ley. Debido a que son normas distintas y se aplican de manera independiente, es posible verificar si existe conformidad de la una con la otra. Ley y Constitución son dos términos distintos de una comparación que tiene como fin discernir si la ley es conforme con la Constitución ${ }^{12}$. Esta independencia no significa lo mismo para la ley y para la Constitución, porque la ley -aunque distinta de la Constitución- no puede aplicarse sino en conformidad con la Constitución ${ }^{13}$. En cambio, la Constitución se aplicaría pura y simplemente. En este sentido, podría decirse que la Constitución es una norma autosuficiente en su aplicación; mas no podría decirse lo mismo de la ley ${ }^{14}$.

La interpretación de la ley conforme con la Constitución es un deber que tiene por objeto la ley; se trata de interpretar la ley. Y el canon de interpretación es la Constitución. Aunque sea riesgoso servirse de una comparación gráfica para ilustrar la forma como opera el principio de interpretación conforme, creo que la imagen de una horma o molde explica la función que en este esquema se le atribuye a la Constitución: la ley debe ajustarse a ella como un objeto a su molde. Es lo que me sugiere, por ejemplo, este texto de Cea: "[en virtud del reconocimiento del principio de supremacía constitucional] la ley y los actos administrativos han quedado en situación de ser revisados, especialmente por los jueces, para

12 Basado en esta premisa, ZAPATA (2008), p. 304, rechaza la posibilidad de leyes que, materialmente, tengan valor constitucional. La Constitución "define explícitamente, y exhaustivamente, los distintos ámbitos competenciales" del constituyente y del legislador. Aunque admite que "los llamados 'Derecho Procesal Constitucional' y 'Derecho Privado Constitucional' podrían constituir un motivo de confusión”.

13 Para salvar la aparente inconsecuencia entre afirmar la independencia de la ley y de la Constitución desde la perspectiva de su aplicación, por una parte, y la necesidad de la ley de conformarse con la Constitución para ser aplicada, por otra, se podría decir que la ley es sustantivamente independiente de la Constitución, pero operativamente o funcionalmente dependiente de la Constitución.

${ }^{14}$ La supremacía constitucional también significa que la interpretación de la Constitución es un proceso propio del ámbito de la jurisdicción constitucional, separado e independiente del proceso de interpretación de la ley. El hecho de que ambos procesos interpretativos converjan en el acto de controlar la constitucionalidad de la ley es una coincidencia que no afectaría la autonomía del proceso de interpretación de la Constitución. De allí que se afirme el diferente ámbito de competencia del Tribunal Constitucional y de los tribunales de justicia, que se entienden como separados e independientes: "la salvaguarda del imperio de la ley en el conocimiento, resolución y ejecución de lo juzgado en causas civiles y criminales corresponde exclusivamente a los tribunales establecidos por la ley, a través de los medios procesales que el legislador establezca mediante los respectivos Códigos de Enjuiciamiento", sentencia Brahm Moura (2007), cons. 7o; el mismo texto en sentencia Lovera Ayca (2008), cons. 11․ Así también lo entiende Zúñiga (2005). Más explícito en Alvarado Andrade (2013), cons. $8^{\circ}$. Otro antecedente que muestra cómo el Tribunal Constitucional entiende que legalidad y constitucionalidad son dos ámbitos independientes, y que solo compete al Tribunal el de la constitucionalidad, es la doctrina de las "cuestiones de legalidad" en la instancia de admisibilidad de requerimientos de inaplicabilidad (SiLVA; 2012, pp. 587 y 588$)$. 
compararlos con la Carta Fundamental y decidir si están o no de acuerdo con ella"15. Por supuesto que no se trata más que de una analogía, pero a mi juicio expresa la idea que subyace a la forma de entender el control de constitucionalidad de la ley.

\section{B. LA INTERPRETACión de la CONSTITUCión}

La interpretación de la ley conforme con la Constitución comporta de manera inevitable una interpretación de la propia Constitución: "la interpretación conforme a la Constitución es una interpretación de normas infraconstitucionales, teniendo como parámetro de control la Constitución, en cuyo caso no se puede evitar interpretar la propia Carta Fundamental". ${ }^{16}$ Y es que, en efecto, interpretar la ley de acuerdo a la norma constitucional es una operación que supone la interpretación simultánea de la ley y de la Constitución. Para saber si una ley es o no conforme con la Constitución, es preciso tener claridad acerca del sentido y alcance de la Constitución; la Constitución debe ser interpretada en el mismo acto en que sirve como canon de interpretación. La cuestión que aquí queda sin responder es, ¿`conforme a qué parámetros se interpreta la Constitución?

Un problema puntual, pero que ilustra los términos de la cuestión que aquí se trata, es el valor que las reglas del Código Civil tienen para el intérprete de la Constitución. ¿Está el intérprete de la Constitución sujeto a las reglas fijadas en la ley? Aldunate muestra que dentro de la doctrina pueden identificarse distintas posiciones respecto del grado de consideración que estas reglas merecen por parte de los jueces constitucionales. Sin embargo, casi sin excepción se afirma la radical independencia que hay respecto de ellas ${ }^{17}$. Y la razón es la supremacía constitucional: sería contradictorio con este principio afirmar que la interpretación de la Constitución está sujeta obligatoriamente a unas reglas de rango legal. En el fondo, esto significaría poner la ley por sobre la Constitución ${ }^{18}$.

La superioridad jerárquica de la Constitución significa que la interpretación del texto constitucional no está sujeta a norma jurídica alguna. Todas las normas jurídicas deben ser necesariamente interpretadas conforme con la Constitución para ser válidas, pero la Constitución es válida sin necesidad de ser interpretada conforme a norma alguna.

\section{La nO INCIDENCia de la ley en la interpretación de la CONSTitución}

La cuestión de la incidencia que la ley podría tener en la interpretación de la Constitución debería resolverse fácilmente respondiendo que la ley no tiene incidencia alguna.

15 CEA (2007), p. 29.

16 Nogueira (2009), p. 168.

17 Aldunate (2000), p. 68.

18 (Ribera; 1989, p. 218; Pfeffer; 1999, p. 110). Al contrario, el civilista Carlos Ducci sostiene que las reglas del Código Civil se aplican también a la interpretación de la Constitución. DucCI (1977), p. 95. Aunque quizá interpreta mejor el parecer de los civilistas hoy la opinión de Ramón Domínguez, quien subordina las reglas del Código Civil a la Constitución: "cuando se trata de interpretar una regla, antes de examinarla a la luz de los elementos gramaticales, históricos, lógicos o sistemáticos, habrá que confrontarla con el texto constitucional” Domínguez (1996). Rodríguez (1990), p. 61, reconoce que la interpretación de la Constitución tiene características propias y singulares. Esta singularidad es, por supuesto, defendida por los constitucionalistas (ZAPATA; 2008, pp. 170-172). Sobre la recepción de los criterios legales en la jurisprudencia del Tribunal Constitucional (Navarro, 1992; Pfeffer, 1999). 
Esta respuesta descansaría fundamentalmente en la superioridad jerárquica de la Constitución, no solo respecto de la ley, sino en términos absolutos (supremus est quem nemo sequitur). La estructura que cobija el orden y las relaciones entre las normas es vertical, en el sentido que las inferiores deben ser interpretadas conforme con las superiores. Siendo la Constitución la norma superior de todas, no tendría sentido pensar que pudiera ser interpretada conforme con la ley, o que la ley pudiera de algún modo determinar su sentido y alcance.

La naturaleza normativa de la Constitución y, consecuentemente, su eficacia directa e inmediata, se apoya en el supuesto de una distinción neta entre Constitución y ley, desde la perspectiva de su aplicación. En efecto, la eficacia normativa de la Constitución significa que es eficaz como norma jurídica con independencia de la ley u otra norma inferior cualquiera. Esta independencia se prueba principalmente en la posibilidad de que el resultado de aplicar la ley sea incompatible con el resultado de aplicar la Constitución ${ }^{19}$. La concepción de la Constitución como norma directa e inmediatamente aplicable asume que su aplicación no depende de la ley en modo alguno. Esta independencia es una garantía de su carácter supremo: se entiende que, si de alguna forma, la eficacia de la Constitución dependiera de la ley, entonces ya no sería suprema. "[La supremacía de la Constitución] repele todo tipo de intento de interpretar la Constitución a partir de normas subconstitucionales, generalmente de orden legal. En efecto, todo el ordenamiento jurídico debe interpretarse a partir de la Constitución"20.

La aplicación exclusiva de la Constitución sería una necesidad (más que una posibilidad) que vendría requerida por el concepto mismo de jurisdicción constitucional. El profesor Aldunate desarrolló esta idea en un trabajo de 1994. Partiendo de la base de la peculiar naturaleza de la Constitución (jurídica y política), se preguntó por la especificidad de la jurisdicción constitucional, es decir, del ámbito jurisdiccional llamado a resolver las interpretaciones antagónicas sobre la Constitución. Y respondió: "la especialidad de la función jurisdiccio-constitucional viene a radicarse en la norma decisora, la constitucional. Se trata de la jurisdicción correspondiente a un derecho específico y justificada en la naturaleza del mismo como cúspide de la jerarquía normativa, y en su función como defensora (la jurisdicción) de esa ubicación” ${ }^{21}$. La jurisdicción constitucional descansa conceptualmente en que las controversias se solucionan "sobre la base de la norma constitucional como único derecho justiciable"22. La posibilidad de que los conflictos puedan solucionarse exclusivamente en base a la Constitución se debe a que es la norma suprema.

En el contexto de la jurisdicción constitucional, entendida como se expuso en el párrafo anterior, es natural que se repruebe cualquier signo que parezca poner en entredicho

\footnotetext{
19 La idea de que pueda infringirse la Constitución exclusivamente también se apoya en este supuesto. Entiendo que para Aldunate (1994), pp. 45 y 46, el objeto propio de la jurisdicción constitucional es la infracción de la Constitución exclusivamente; y el recurso de protección -entre otros- es un instrumento idóneo de la jurisdicción constitucional, porque la Constitución es la única norma aplicada y aplicable a través suyo (pp. 58 y 59).

20 Nogueira (2009), p. 157.

21 Aldunate (1994), p. 44.

22 Aldunate (1994), p. 45.
} 
la aplicación directa e inmediata de la Constitución. Así, por ejemplo, Aldunate critica la sentencia del Tribunal Constitucional rol $78^{23}$, porque en la argumentación sobre la constitucionalidad de la Ley Orgánica del Banco Central, el Tribunal incorporó la propia ley "como cartabón del control al que está siendo sometida. [Y] resulta incuestionable que para calificar la constitucionalidad de una L.O.C. no se puede hacer referencia a su propio contenido normativo" ${ }^{24}$. Cea también habría reprochado este proceder, porque una aplicación importante del principio de supremacía constitucional "yace en que la interpretación y aplicación de cualquier precepto jurídico deben siempre ser efectuadas en defensa de la Constitución y nunca de las disposiciones subordinadas a ella"25. El propio Tribunal Constitucional se encargó de aclarar el punto, cuando -quizá- se vio inducido por una de las partes a identificar la ley con la Constitución: "[El Tribunal Constitucional] no puede interpretar la Constitución como si las regulaciones legales fueran las que fijaran su sentido y alcance. Son las leyes las que deben interpretarse conforme a la Constitución, y no esta en base a las leyes" 26 .

La Constitución es el canon de interpretación de la constitucionalidad de la ley. Para cumplir esta función, la Constitución debe ser interpretada. Pero la interpretación de la Constitución no puede estar influida por la ley porque, si lo estuviera, entonces se estaría igualando la ley con la Constitución. Así podría resumirse la doctrina dominante en la materia.

Desde otro ángulo, aceptar que el sentido de la Constitución pudiera ser influido por la ley, sería equivalente a reconocerla como canon de constitucionalidad. Es esto de lo que se da cuenta Zapata cuando dice: "el parámetro de constitucionalidad no es otro que el conjunto de valores, principios y normas contenidos o referidos (...) en el documento intitulado Constitución Política de la República de Chile. (...) No parece correcto, ni necesario, por tanto, que se 'suban' a la Constitución normas del derecho codificado u orgánico constitucional que a algún intérprete puedan parecer particularmente importantes o sensatas" 27 . De lo mismo se percató el Tribunal Constitucional, y por eso habría afirmado que "El parámetro de referencia que se tiene en cuenta al resolver una inaplicabilidad, es solo la Constitución. La norma contra la cual debe examinarse el precepto legal objetado es únicamente la Constitución, no la ley. (...) El Tribunal [Constitucional] no resuelve una inaplicabilidad en base a una norma legal; el precepto legal es el objeto del examen, pero no su referente. (...) Las leyes, en consecuencia, no pueden ser, a la vez, norma examinada y norma examinante. (...) De ahí que no pueda 'constitucionalizar' preceptos legales. Esto es, darle rango constitucional a normas dictadas por el poder legislativo" 28 .

\footnotetext{
23 Control de constitucionalidad respecto del proyecto de ley orgánica constitucional sobre el Banco Central (1989).

24 Aldunate (1998), p. 117.

25 CEA (1984), p. 8.

26 Coloma Correa (2012), cons. 9o.

27 Zapata (2008), p. 307. Por lo mismo, le parece inconveniente la doctrina del Bloque de Constitucionalidad, si en él se comprenden disposiciones legales, ZAPATA (2008), p. 308. En el mismo sentido puede leerse la prevención de los ministros Carmona y García en Requerimiento respecto de la constitucionalidad del Convenio Internacional para la Protección de Obtenciones Vegetales (UPOV-91) (2011), cons. 15².

28 Agrícola Bauzá (2009), cons. 6º.
} 


\section{LAS INCONSISTENCIAS DEL PRINCIPIO DE INTERPRETACIÓN CONFORME}

Resulta evidente que la Constitución debe ser interpretada cada vez que es aplicada, y es aplicada cada vez que sirve como canon de interpretación. Pero ¿̨cuál es el sentido exacto de esta afirmación, si es que la misma Constitución requiere ser interpretada para servir como canon de interpretación? Balaguer reconoce la interpretación conforme como "una operación de ajuste, no solo de la norma contenida en la ley, sino de la propia Constitución, apurando, en ese intento conservador, las posibilidades de ambos textos, y yendo tanto al telos de la norma a aplicar, como al de los preceptos constitucionales que deben servir de medida de la congruencia de esa norma con la Constitución”. ${ }^{29}$ Luego, la Constitución es un canon que se construye en el mismo acto en que orienta al intérprete que controla la constitucionalidad de la ley. Esta dinámica de la norma constitucional significa que sirve como canon al mismo tiempo que se construye como canon.

La cuestión que ahora interesa abordar es si la ley incide en la fijación del sentido de la Constitución. Aunque, como se acaba de ver, la respuesta sería en principio negativa, hay buenas razones para pensar lo contrario. Un examen de la jurisprudencia del Tribunal Constitucional en el control de constitucionalidad de la ley conduce precisamente a pensarlo así.

A continuación se ofrece un análisis sistematizado de una selección de fallos del Tribunal Constitucional, en que se distinguen los del control a priori de los del control a posteriori $y$, de entre estos, se distinguen los de control directo y los de control indirecto de la ley.

\section{A. CONTROL A PRIORI}

En este apartado se comprende el análisis de algunas sentencias dictadas en el ejercicio de las atribuciones de control de constitucionalidad de proyectos de ley, que corresponden a los $\mathrm{N}^{\circ}$ s 1, 3 y 4 del artículo 93 de la Constitución.

Un ejemplo temprano es la sentencia rol 217 y 218 (acumulados), de 10 de julio de 1995, que resolvió un requerimiento presentado contra una indicación presidencial que modificaba el estatuto docente ${ }^{30}$. El Tribunal Constitucional debió decidir si era constitucional la disposición legal -artículo $4^{\circ}$ transitorio de la ley $\mathrm{N}^{\circ} 19.070$ - que fijó la fecha de pago de un complemento adicional por zona a los profesores. El vicio alegado de inconstitucionalidad era la afectación del derecho de propiedad de los profesores, que habrían tenido derecho al complemento adicional desde una fecha anterior a la fijada por el artículo $4^{\circ}$ transitorio. La premisa que sentó el Tribunal Constitucional para juzgar la constitucionalidad de la norma fue: "Que el contexto de la ley sirve para ilustrar el sentido de cada una de sus partes de manera que exista entre ellas la debida correspondencia y armonía” ${ }^{31}$. Antes,

\footnotetext{
29 Balaguer (1997), p. 112.

30 Requerimiento respecto de la indicación $N^{o} 148$, de S. E. el Presidente de la República, en el proyecto de ley que introduce modificaciones a la Ley No 19.070, que Aprueba el Estatuto de los Profesionales de la Educación (1995).

31 Requerimiento respecto de la indicación $N^{o} 148$, de S. E. el Presidente de la República, en el proyecto de ley que introduce modificaciones a la Ley No 19.070, que Aprueba el Estatuto de los Profesionales de la Educación (1995), cons. $6^{\circ}$.
} 
en el considerando 50 ${ }^{\circ}$, se hizo un pormenorizado análisis de la ley 19.070 que le llevó a establecer dos antecedentes fundamentales para el fallo: que el complemento adicional era de naturaleza distinta a las asignaciones, y que los obligados al pago eran los sostenedores. Estas conclusiones enervaron los motivos que los requirentes tenían para alegar que el derecho al complemento adicional era anterior a la fecha fijada por la disposición impugnada. Asentadas que fueron estas dos conclusiones, cerró el Tribunal diciendo que la disposición impugnada "no es inconstitucional, pues no vulnera la garantía prevista en el $\mathrm{N}^{\circ} 24$ del artículo 19 de la Constitución"32.

Quisiera llamar la atención sobre la función que la Constitución cumplió como canon de interpretación del artículo $4^{\circ}$ transitorio de la ley 19.070. Aparentemente, al menos, no cumplió ninguna. El problema de si la fijación de la fecha de pago del complemento por zona a los profesores vulneraba o no el derecho de propiedad de los docentes, no fue resuelto por la Constitución. Pero -y esto es lo que más importa-, ¿cómo supo el juez que el artículo $19 \mathrm{~N}^{\circ} 24$ de la Constitución no prohibía al legislador fijar una determinada fecha para el pago del complemento por zona a los profesores? Lo supo a través de la ley; en este caso concreto, el contenido del derecho de propiedad fue establecido con ayuda de la ley. La lectura completa de la sentencia rol 217 y 218 (acumulados) deja bastante claro lo que se intenta transmitir en este breve comentario: que la decisión de inconstitucionalidad siguió al juicio de legalidad. La declaración de que la disposición no afectaba el derecho de propiedad fue el broche de un razonamiento que ya estaba completo.

Otro ejemplo lo ofrece la sentencia rol 271, de 31 de marzo de 1998, que se pronunció sobre dos disposiciones del proyecto de ley que modificó el Decreto Ley No 701/74 sobre fomento forestal ${ }^{33}$. Una de las normas sobre las que debió pronunciarse el Tribunal Constitucional fue el numeral 5 del artículo 1 del proyecto de ley, que definía quién era el juez competente para conocer las reclamaciones contra las resoluciones de la CONAF que denegaren una solicitud. Pero ante la duda de a qué solicitudes se refería la disposición en cuestión, el Tribunal decidió que debería entenderse que se trataba de las solicitudes de declaración de terrenos con aptitud preferentemente forestal, mencionadas en el numeral 4 del artículo 1 del proyecto de ley. La referencia a un artículo del mismo proyecto de ley que estaba siendo controlado, para resolver una duda de constitucionalidad, demuestra que también en este caso el Tribunal Constitucional satisfizo la exigencia del control de constitucionalidad, interpretando la Constitución según los términos de la ley (v.gr. del proyecto de ley). Las exigencias que la Constitución, en cuanto canon de interpretación, planteó a la norma que fue controlada, fueron satisfechas con una remisión a elementos de la propia norma que fue objeto del control.

\footnotetext{
32 Requerimiento respecto de la indicación $N^{o} 148$, de S. E. el Presidente de la República, en el proyecto de ley que introduce modificaciones a la Ley No 19.070, que Aprueba el Estatuto de los Profesionales de la Educación (1995), cons. $6^{\circ}$. El hecho de haber sido Servando Jordán, a la sazón ministro de la Corte Suprema, el redactor del fallo es una circunstancia que debe ser tenida en cuenta, porque quizá sirva para explicar el estilo de la sentencia.

33 Control de constitucionalidad respecto del proyecto de ley que modifica el Decreto Ley $N^{\circ} 701$, de 1974, sobre Fomento Forestal (1998).
} 
Un caso semejante al de la sentencia rol 271 fue el de la sentencia rol 297, de 11 de noviembre de $1999^{34}$. Este caso se produjo con ocasión del control de constitucionalidad de un proyecto de ley que contenía algunas normas sobre racionalización del sector Hacienda. La disposición 9a transitoria del proyecto de ley regulaba la primera provisión de los cargos creados por el artículo 19 del proyecto, pero sin señalar qué cargos eran estos. Entonces el Tribunal decidió que la interpretación de dicha disposición que resultaba conforme con la Constitución era entender que se refería a los doce cargos creados por el mentado artículo 19. Más allá de la perogrullada que este resultado representa, ejemplifica cómo el intérprete se vale de la misma ley para resolver las dudas que plantea sobre su constitucionalidad.

\section{B. Control $A$ POSTERIORI Directo}

El control directo de constitucionalidad de la ley vigente lo efectúa el Tribunal Constitucional alternativamente a través de dos atribuciones: las de los $\mathrm{N}^{\circ}$ s 6 y 7 del artículo 93 de la Constitución. Aunque las diferencias entre la jurisprudencia de inaplicabilidad e inconstitucionalidad no es significativa desde el punto de vista de este trabajo, he preferido de todos modos tratarlas separadamente por un motivo didáctico.

\section{La inconstitucionalidad}

Cuantitativamente, el número de sentencias que se analizarán a continuación puede parecer bajo para apoyar las conclusiones que se van a presentar, pero creo que hay en ellas un patrón hermenéutico consistente, que justifica ponerlos como casos de una práctica típica del Tribunal Constitucional.

En la sentencia que declaró inconstitucional la expresión "gratuitamente" del artículo 595 del Código Orgánico de Tribunales, hay algunos elementos que sugieren la incidencia que tiene la interpretación de la ley en la satisfacción de los estándares del control de constitucionalidad ${ }^{35}$. En primer lugar, destaca la prolija relación de los antecedentes históricos de la institución del turno gratuito de los abogados, que recorre el arco que va desde el Derecho Romano al artículo 595 del Código Orgánico de Tribunales, incluidas las reformas sufridas por este artículo hasta la actualidad. ¿Qué relación tiene la historia de la institución con su constitucionalidad? ¿De qué manera los antecedentes históricos del artículo 595 del Código Orgánico de Tribunales pueden influir en el juicio de constitucionalidad? En segundo lugar, dice la sentencia que "para poder determinar si se infringe la igualdad ante la ley, es necesario atender (...) a la finalidad perseguida por el legislador para intervenir el derecho fundamental de que se trata" ${ }^{36}$. ¿Por qué la intención del legislador es un elemento relevante para decidir la constitucionalidad de una norma? Conocer la finali-

34 Control de constitucionalidad respecto del proyecto de ley que concede beneficios económicos al personal del Servicio de Impuestos Internos, del Consejo de Defensa del Estado, de la Dirección de Presupuestos y de las Fuerzas Armadas, y contiene otras normas sobre racionalización del sector hacienda (1999).

35 Requerimiento de inconstitucionalidad respecto del texto integro del artículo 595 del Código Orgánico de Tribunales (2009).

36 Requerimiento de inconstitucionalidad respecto del texto integro del artículo 595 del Código Orgánico de Tribunales (2009), cons. 58․ 
dad de la norma es relevante, porque en ella se afirma el juicio de idoneidad, necesidad y proporcionalidad de la restricción legal, contesta el Tribunal Constitucional. Lo que en este punto confirma la hipótesis del trabajo es que, para determinar la intención del legislador, la Constitución es innecesaria. El juicio de constitucionalidad vendrá como corolario de una operación típica de interpretación de la ley. Por último, la sentencia compara el turno de los abogados con otras formas en que legislador ha cumplido la obligación estatal de prestar asistencia jurídica a quien carece de los medios para pagarla. Concretamente menciona la ley 19.718 (creó la Defensoría Penal Pública) y otros varios antecedentes ${ }^{37}$. Todo lo cual le lleva a demostrar el carácter excepcionalísimo del turno de los abogados. Pero esta carga pública gratuita, que de suyo no resulta contraria a la igualdad, es inconstitucional cuando se la compara con otras cargas públicas que son remuneradas (servicio militar e integración de mesas electorales como vocal). En este argumento, el recurso a leyes emparentadas con el supuesto del artículo 595 del Código Orgánico de Tribunales, es decisivo para determinar la inconstitucionalidad de la norma. La Constitución no dice absolutamente nada acerca de si las cargas públicas deben ser remuneradas o no. Luego, de no ser por esas referencias a la ley, ¿cómo habría podido el juez resolver la cuestión?

La sentencia del Tribunal Constitucional que declaró inconstitucional el inciso $1^{\mathrm{o}}$ del artículo 171 del Código Sanitario, es un buen ejemplo del entrelazamiento ley-Constitución en el razonamiento de los jueces ${ }^{38}$. En efecto, el núcleo del problema que el Tribunal debió resolver fue si la restricción de la disposición impugnada-que para dar curso a los reclamos contra multas impuestas por el Servicio de Salud el infractor debía acompañar el comprobante de haber pagado la multa- "se encuentra o no en los márgenes tolerados por la Carta Fundamental" ${ }^{39}$. Para ello, se especificaron los puntos a dilucidar, que fueron: si la limitación se encontraba suficientemente especificada en la ley, si perseguía un fin lícito, si resultaba idónea para alcanzar el fin que se proponía y si era proporcional al fin. Esta última cuestión, que se desglosó en el análisis de tres específicos fines, se convirtió en la piedra angular del razonamiento. La sentencia analizó la relación que guardaba la restricción del artículo 171 inc. $1^{\circ}$ con el respeto a la presunción de legalidad de los actos administrativos, con evitar la litigación dilatoria y con garantizar la eficacia de las multas. De antemano sabía el juez que ninguna de estas cuestiones tenía respuesta en la Constitución. ¿Dónde buscará el juez, entonces, la respuesta? En la ley. De este modo, la sentencia llegó a la conclusión de que para evitar la litigación dilatoria no se justificaba la limitación, ya que la propia ley disponía de mecanismos al efecto: el examen de admisibilidad y la condenación en $\operatorname{costas}^{40}$. La presunción de legalidad de los actos administrativos tampoco era un fin que justificara el solve et repete, porque el artículo 172 del Código Sanitario aseguraba

\footnotetext{
37 Requerimiento de inconstitucionalidad respecto del texto integro del artículo 595 del Código Orgánico de Tribunales (2009), cons. 53․

38 Pronunciamiento de oficio sobre la inconstitucionalidad de algunas de las expresiones contenidas en el inciso primero del artículo 171 del Código Sanitario (2009).

39 Pronunciamiento de oficio sobre la inconstitucionalidad de algunas de las expresiones contenidas en el inciso primero del artículo 171 del Código Sanitario (2009), cons. 10.

40 Pronunciamiento de oficio sobre la inconstitucionalidad de algunas de las expresiones contenidas en el inciso primero del artículo 171 del Código Sanitario (2009), cons. 13º.
} 
la eficacia de la resolución administrativa aunque fuera reclamada ante tribunales ${ }^{41}$. Por último, el argumento de la eficacia de las multas de la autoridad administrativa se contestó con el mismo artículo 172 del Código Sanitario, al que deberían agregársele un conjunto de otros instrumentos relativos a los efectos de la reclamación judicial sobre la ejecución de la sanción ${ }^{42}$. Hasta aquí, el Tribunal no tuvo necesidad de invocar la Constitución. Para demostrar que la norma se hallaba fuera de los márgenes establecidos por la Constitución, le bastó una interpretación sistemática de la ley. En buenas cuentas, el inciso $1^{\circ}$ del artículo 171 del Código Sanitario era inconstitucional porque estaba de más en el ordenamiento ${ }^{43}$ : los fines que justificaban su existencia ya eran garantizados por otras normas legales.

Uno de los votos de la sentencia rol 1723, que resolvió sobre la constitucionalidad del artículo 2331 del Código Civil, es un ejemplo del grado de incidencia que la ley tiene en la determinación de los alcances de la Constitución como canon de interpretación ${ }^{44}$. Un primer argumento para considerar constitucional la disposición cuestionada consistió en invocar el artículo 40 de la ley $\mathrm{N}^{\circ} 19.733$-que habilita a los afectados por el delito de injuria a reclamar indemnización por daño moral-, para demostrar que la restricción del artículo 2331 del Código Civil no era tan absoluta como parecía a primera vista, considerando que en muchos casos las imputaciones injuriosas son delitos. Un segundo argumento, para aquellos casos que no quedaran comprendidos por el artículo 40 de la ley $\mathrm{N}^{\circ} 19.733$, fue que el estatuto general de la responsabilidad en el Código Civil (artículos 2314 y 2329) ofrecería una solución, es decir, los supuestos más relevantes de daño moral por injuria serían potencialmente indemnizables pese a la prohibición del artículo 2331 del Código Civil. En suma, "una interpretación armónica de las normas que integran el ordenamiento jurídico vigente lleva a la conclusión de que, solo en algunos casos, la aplicación del artículo 2331 del Código Civil podría afectar la protección que la Constitución Política brinda a la honra de las personas" ${ }^{45}$. Como se puede ver en este voto, los argumentos de la inconstitucionalidad descansan en la ley; son argumentos que pretenden demostrar la constitucionalidad del artículo 2331 del Código Civil destacando la armonía que guarda con otras leyes.

\section{La inaplicabilidad}

La inaplicabilidad es un mecanismo de interpretación de la ley, pero también de la Constitución. Lo que ahora interesa destacar es cómo, a través de la inaplicabilidad, la Constitución no es un canon de interpretación independiente de la ley. En la inaplicabili-

\footnotetext{
41 Pronunciamiento de oficio sobre la inconstitucionalidad de algunas de las expresiones contenidas en el inciso primero del artículo 171 del Código Sanitario (2009), cons. 14º.

42 Pronunciamiento de oficio sobre la inconstitucionalidad de algunas de las expresiones contenidas en el inciso primero del artículo 171 del Código Sanitario (2009), cons. 15.

43 Pronunciamiento de oficio sobre la inconstitucionalidad de algunas de las expresiones contenidas en el inciso primero del artículo 171 del Código Sanitario (2009), cons. 16º.

44 Proceso de inconstitucionalidad iniciado de oficio por el Tribunal Constitucional en relación al artículo 2331 del Código Civil (2011). Esta sentencia, que rechazó la inconstitucionalidad por falta de quórum, tuvo varios votos.

45 Este argumento es de los ministros Vodanovic, Peña y Navarro. Se subentiende que aquellos casos en que la persona afectada no podría reclamar indemnización por el daño moral, no son suficientes como para justificar la declaración de inconstitucionalidad.
} 
dad, la ley incide en la interpretación de la Constitución. Esto es lo que se puede constatar en la jurisprudencia.

Un capitán de Carabineros requirió al Tribunal Constitucional la declaración de inaplicabilidad de los artículos $299 \mathrm{~N}^{\circ} 3,431$ y 433 del Código de Justicia Militar ${ }^{46}$. El requerimiento estuvo motivado por un juicio seguido en su contra por el delito de incumplimiento de deberes militares, descrito en el artículo 299 Nº 3 del Código de Justicia Militar. Lo que alegó el requirente fue que la descripción de la conducta por la que se le juzgaba no satisfacía el principio de tipicidad, configurándose un supuesto de ley penal en blanco.

Para resolver la inaplicabilidad del artículo 299 Nº 3 del Código de Justicia Militar, el Tribunal Constitucional debió elucidar si la norma describía al menos el núcleo central de la conducta que sancionaba. Esto significó dos cosas: "analizar el estándar de 'densidad normativa' del tipo aplicado" 47 y verificar si los reglamentos a que se remitía el artículo 431 complementaban el tipo del artículo $299 \mathrm{~N}^{\circ} 3$. Es lo que hizo, y concluyó que los deberes militares "no figuran de forma concreta y específica en normas legales ni reglamentarias"; 48 que "el tipo penal establecido en el artículo $299 \mathrm{~N}^{\circ} 3$ (...) resulta incompleto" ${ }^{49}$ y "no existe complemento reglamentario suficiente para que el tipo de incumplimiento de deberes militares se baste a sí mismo" ${ }^{\circ}$. El Tribunal Constitucional declaró la inaplicabilidad de los artículos impugnados del Código de Justicia Militar.

Lo que interesa subrayar de la sentencia Silva Martínez es la naturaleza legal y reglamentaria del marco en el que se desenvolvió el análisis de los vicios de inconstitucionalidad. En el fondo, el Tribunal debió interpretar los artículos 299 No 3 y 431, y los reglamentos que podían complementarlos, para decidir si eran conformes con la Constitución. Dicho de otra forma, el resultado del juicio de constitucionalidad dependió del resultado de la interpretación de la ley.

En la sentencia rol 1145 se acogió un requerimiento de inaplicabilidad interpuesto en representación del alcalde de la Municipalidad de Arauco, que solicitó la declaración de inconstitucionalidad del artículo 238 del Código de Procedimiento Civil y del artículo 32 inc. $2^{\circ}$ de la ley $\mathrm{N}^{\circ} 18.695$ Orgánica de Municipalidades ${ }^{51}$. El motivo del requerimiento fue el arresto del alcalde ordenado por el juez civil, como apremio para que la Municipalidad diera cumplimiento a la sentencia que lo condenó al pago de lo adeudado por el arrendamiento de un inmueble. El Tribunal circunscribió la cuestión a resolver en el considerando 7º: decidir si la aplicación de los artículos impugnados constituía una vulneración a las garantías de los $\mathrm{N}^{\circ}$ s 1 y 7 del artículo 19 de la Constitución y, además, un supuesto de prisión por deudas.

Para decidir si el supuesto del artículo 32 inc. 20 de la ley orgánica de municipalidades, en relación al artículo 238 del Código de Procedimiento Civil, era un caso de prisión

\footnotetext{
46 Silva Martinez (2011).

47 Silva Martínez (2011), cons. 14º.

48 Silva Martínez (2011), cons. 12.

49 Silva Martinez (2011), cons. 16º.

50 Silva Martinez (2011), cons. $18^{\circ}$.

51 Municipalidad de Arauco (2009).
} 
por deudas, el Tribunal definió que "era indispensable identificar la naturaleza de la obligación que ha motivado la orden de arresto”. Porque si es de naturaleza legal, es constitucional; en cambio, si es de naturaleza contractual, es inconstitucional ${ }^{52}$. La Constitución no da ninguna pista de cómo deba calificarse la naturaleza de la obligación. En este punto, mal podría entenderse que la ley será interpretada conforme con la Constitución. De hecho, el Tribunal recurrió a la historia de la ley 18.695 para determinar que la naturaleza de la obligación era legal ${ }^{53}$. En consecuencia, concluyó el Tribunal Constitucional, "la orden de arresto fue despachada con el objeto de asegurar el cumplimiento de una obligación de hacer prevista en la ley (...). Así, no puede estimarse que, en la especie, se configure la hipótesis propia de una 'prisión por deudas', puesto que la obligación cuyo cumplimiento se procuraba asegurar mediante la imposición de una medida de arresto se encuentra prevista en la ley" ${ }^{54}$.

Con el mismo razonamiento con que rechazó el argumento de la prisión por deudas, desechó la supuesta vulneración de la garantía del artículo 19 N 1: "La situación que se examina [orden de arresto para asegurar la ejecución de una sentencia que ordena el pago de una deuda] corresponde justamente a una de aquellas actuaciones legítimas de la autoridad jurisdiccional" 55 . Legítima en este caso significa legal. Respecto de la garantía del $N^{\circ} 7$ del artículo 19, el Tribunal consideró que en el caso concreto la orden de arresto resultaba inconstitucional, porque para la fecha el alcalde ya había cumplido con lo ordenado. En palabras del Tribunal, la medida es contraria a la Constitución "porque va más allá de lo contemplado en las normas legales que sirvieron de fundamento a la medida decretada" 56 . En otras palabras, se declara la inconstitucionalidad del acto (orden de arresto), porque carece de fundamento legal; es inconstitucional porque es ilegal.

En otro caso, el Tribunal Constitucional hubo de resolver sobre la inaplicabilidad del artículo 207 letra b) del decreto con fuerza de ley $\mathrm{N}^{\circ} 1 / 2009$, del Ministerio de Transportes y Telecomunicaciones ${ }^{57}$. La norma, que ordena al juez de policía local la suspensión de la licencia de conducir a quien acumule dos infracciones graves dentro de un determinado lapso, fue impugnada por un conductor en el marco del proceso de suspensión de licencia por acumulación de infracciones. La razón constitucional que se dirigió contra la aplicación del precepto fue que infringía el principio non bis in idem y no cumplía el principio de tipicidad.

Para decidir si el supuesto del artículo 207 letra b) del decreto con fuerza de ley $\mathrm{N}^{\circ}$ 1/2009 era inconstitucional, el Tribunal debió discernir si era contrario al principio non bis in idem. Y para saber esto, analizó la normativa legal. Concluyó que era inconstitucional, porque en los procesos vinculados (el de la infracción y el de la suspensión) se tutela el mismo bien jurídico; porque el proceso de suspensión no juzga un hecho delictivo nuevo

\footnotetext{
52 Municipalidad de Arauco (2009), cons. 26․

53 Municipalidad de Arauco (2009), cons. $28^{\circ}$ y $29^{\circ}$.

54 Municipalidad de Arauco (2009), cons. 31\%.

55 Municipalidad de Arauco (2009), cons. 34\%.

56 Municipalidad de Arauco (2009), cons. 43․

57 Jordán Astaburuaga (2012).
} 
y, porque "está reservado (...) a situaciones del todo ajenas a las que se ventilan en este caso" 58 . Por otra parte, para determinar si la norma impugnada satisfacía el principio de tipicidad, el Tribunal examinó el texto legal y concluyó que no, porque en él no se describía ninguna acción que "pueda configurar un hecho típico"

La inaplicabilidad de la norma que prescribe la suspensión de la licencia de conducir por acumulación de infracciones, se fundamentó en un análisis del texto legal a la luz de unas exigencias constitucionales (non bis in idem y tipicidad). La interpretación de la ley exigida por el canon constitucional del que dependía su aplicación, se presenta como un factor determinante en el resultado del juicio de constitucionalidad a la que se haya sometida. Lo interesante es que la interpretación de la ley fue un proceso que se movió dentro del marco del texto de la ley. La Constitución no sirvió para resolver las preguntas decisivas del juicio: ¿consagra la norma un supuesto contrario al non bis in idem?, ¿satisface la norma el principio de tipicidad? Estas preguntas fueron resueltas con criterios de interpretación de la ley; y solo una vez que fueron respondidas se calificó su resultado como inconstitucional.

Otro caso ilustrativo de cómo en la práctica el juicio de constitucionalidad de la ley está influido por la ley, es el de la sentencia de inaplicabilidad rol 1399 y 1469 (acumulados), del 4 de noviembre de $2010^{60}$. La sentencia resolvió un requerimiento presentado contra el artículo $42 \mathrm{~N}^{\circ} 1$ inciso final de la ley sobre impuesto a la renta, que consideraba al práctico de puerto como un empleo o trabajo dependiente, y le aplicaba el impuesto correspondiente, que era más gravoso que el de las profesiones liberales ${ }^{61}$. El requirente alegó que el trabajo de práctico de puerto era equivalente a una profesión liberal y que, en consecuencia, debía aplicársele el impuesto propio de los trabajadores independientes. Al tratársele como un trabajador dependiente, se estaba infringiendo su derecho constitucional a la igualdad ante la ley.

El Tribunal Constitucional definió que "en el caso sub lite el elemento toral para discernir el régimen impositivo aplicable a las rentas que en el ejercicio de su actividad obtienen los prácticos de puerto autorizados es el alusivo a determinar si tal actividad lucrativa es dependiente o independiente" ${ }^{62}$. Para dilucidar el punto estableció, en primer lugar, que el sentido del vocablo "dependencia" era el propio de la relación laboral, porque así se infiere del "propio epígrafe con que comienza en la referida ley la regulación de los impuestos de segunda categoría ('De las rentas del trabajo')”“3. En segundo lugar, invocó el inciso segundo del artículo 18 de la ley orgánica de la Dirección General del Territorio Marítimo y de Marina Mercante (decreto con fuerza de ley $\mathrm{N}^{\circ} 292$, de 1953), en donde consta que el práctico no es un empleado (no hay dependencia) ${ }^{64}$. De estos dos antecedentes concluyó que "la asimilación que el precepto legal impugnado en estos autos hacía de los prácticos

\footnotetext{
58 Jordán Astaburuaga (2012), cons. 5.

59 Jordán Astaburuaga (2012), cons. 6º.

60 Paúl Latorre (2010).

${ }^{61}$ Esta disposición fue derogada en 2007 por la ley N²0.219 (2007). Resultaba más gravosa porque impedía a los prácticos de puerto acogerse al beneficio tributario del artículo 50 bis del decreto ley $\mathrm{N}^{\circ} 824$ (1974).

62 Paúl Latorre (2010), cons. $18^{\circ}$.

63 Paúl Latorre (2010), cons. 19.

${ }^{64}$ Paúl Latorre (2010), cons. 19.
} 
(...) con los trabajadores dependientes o asalariados, en lugar de hacerlo con los trabajadores independientes, necesariamente riñe con el principio de igualdad de trato" ${ }^{65}$. En apoyo de esta conclusión, acudió a la historia de la ley que derogó el precepto impugnado, citando el Mensaje y el Primer Informe de la Comisión de Hacienda del Senado ${ }^{66}$.

Los argumentos que la sentencia invocó para declarar inconstitucional el inciso final del $\mathrm{N}^{\circ} 1$ del artículo 42 de la ley sobre impuesto a la renta son legales. De la misma manera habría podido proceder un tribunal ordinario de justicia. La única diferencia que podría señalarse entre la sentencia del Tribunal Constitucional y una de los tribunales ordinarios es la conclusión. Pero la conclusión no es un argumento. Sin embargo, esta circunstancia no es reprochable al Tribunal Constitucional, porque no se le puede pedir a la Constitución que defina si el práctico de puerto es un trabajo de naturaleza dependiente o independiente. Esta es una definición propia del legislador. En el caso, había fundamento legal para considerar que era dependiente e independiente. Lo que el Tribunal Constitucional hizo fue resolver la antinomia en base a criterios legales ${ }^{67}$.

\section{El CONTROL A POSTERIORI INDIRECTO}

En este apartado se comprenden las atribuciones de los $\mathrm{N}^{\circ}$ s 4 y 16 del artículo 93 de la Constitución: el control de los decretos con fuerza de ley y de los decretos supremos que ejecutan leyes. Cierto es que ninguna de estas dos atribuciones de control de constitucionalidad tiene por objeto directo la ley. Por lo mismo, la referencia a ellas podría considerarse ajena al foco de la investigación. Sin embargo, en el ejercicio de estas atribuciones, la ley se convierte en un elemento indispensable del juicio de constitucionalidad. El Tribunal Constitucional no prescinde - no puede prescindir- de la ley para determinar si el decreto supremo o el decreto con fuerza de ley es constitucional o inconstitucional. De nuevo, como se ha visto con ocasión de otras atribuciones, la interpretación de la ley se torna en factor decisivo para ponderar la satisfacción de los estándares del control de constitucionalidad.

\section{El control de la potestad reglamentaria de ejecución}

En principio, el control de constitucionalidad de la potestad reglamentaria de ejecución por parte del Tribunal Constitucional, consiste en una confrontación directa entre el decreto supremo y la Constitución. Sin embargo, esto no es así normalmente. Lo que suele ocurrir en el control de constitucionalidad de los decretos supremos es una verificación de la legalidad del mismo: si resulta conforme con la ley, entonces se descarta la inconstitucionalidad $^{68}$. Esto no tiene nada de raro, puesto que en los requerimientos de inconstitucionalidad típicamente se invoca la infracción del principio de reserva legal por parte del Ejecutivo; el vicio de inconstitucionalidad que habitualmente se le reprocha al Presidente de

\footnotetext{
65 Paúl Latorre (2010), cons. 220.

66 Paúl Latorre (2010), cons. $23^{\circ}$ a $25^{\circ}$.

67 Realmente este no parece haber sido un problema de interpretación, porque el sentido del artículo $42 \mathrm{~N}^{\circ}$ 1 inciso final era claro. Lo que había era una incompatibilidad entre dicho artículo y el artículo 18 del decreto con fuerza de ley $\mathrm{N}^{\circ} 292$ (1953). Los antecedentes legislativos de la derogación del artículo $42 \mathrm{~N}^{\circ} 1$ inciso final fueron determinantes en la decisión.

68 SilVA (2009), pp. 157-179.
} 
la República es haber invadido la competencia del Congreso, al excederse de los términos de la ley que debía ejecutar. En la práctica, el control de constitucionalidad de los decretos supremos se resuelve en un control de legalidad. Esto significa que cuando el decreto supremo es conforme con la ley, entonces es conforme con la Constitución. Un caso que ilustra lo que se trata de decir es el de la sentencia rol 577, de 26 de abril de 2007, conocido como Estero Carén ${ }^{69}$.

En el caso Estero Carén el Tribunal Constitucional rechazó el requerimiento de inconstitucionalidad contra el decreto supremo $N^{\circ} 80 / 2006$. Este decreto estableció las normas de emisión de sustancias contaminantes aplicables a los desagües de los tranques de relave de una mina de Codelco al estero Carén, en el norte del país. Se alegó que el decreto supremo $N^{\circ} 80$ infringió la Constitución, porque las normas de emisión que fijó estarían justificando la contaminación de las aguas, mediante el establecimiento de un régimen excepcional para mantener la operación de la minera estatal. Uno de los puntos que el Tribunal debía esclarecer era si los márgenes de molibdeno y sulfatos tolerados por el decreto supremo $\mathrm{N}^{\circ} 80$ eran contrarios al artículo $19 \mathrm{~N}^{\circ} 8$ de la Constitución. Para despejar la cuestión ofreció el siguiente argumento: "a pesar de que no tiene el carácter de una ley interpretativa de la Constitución, no puede prescindirse de los conceptos que formula -'para todos los efectos legales'- el artículo $2^{\circ}$ de la Ley $\mathrm{N}^{\circ} 19.300(\ldots)$ para apreciar si la presencia de un contaminante es más que un impacto o alteración del ambiente y merece ser calificada de contaminación” ${ }^{\prime 0}$. En el considerando $16^{\circ}$ el Tribunal descartó que el decreto supremo $\mathrm{N}^{\circ} 80$ hubiera infringido las garantías de los $\mathrm{N}^{\circ}$ s 2 y 22 del artículo 19 afirmando que "la autoridad administrativa (...) ha actuado legalmente habilitada (...), de modo que es la ley y no la mera voluntad de la administración la que ha permitido la existencia de normas de emisión diferentes para distintos lugares del país". Por último, en el considerando $22^{\circ}$ desechó la supuesta infracción al artículo 7 de la Constitución diciendo que "la competencia ministerial para aprobar normas de emisión es indiscutible conforme al artículo 40 de la Ley $\mathrm{N}^{\circ} 19.300$ (...), por lo que mal puede estimarse vulnerado el artículo $7^{\circ}$, inciso segundo, de la Constitución Política”. Lo interesante del caso es que el juicio de constitucionalidad del decreto impugnado se centró en demostrar que el Ejecutivo actuó dentro de su competencia y, por lo tanto, el resultado no podía ser calificado de inconstitucional.

La sentencia Estero Carén es un ejemplo de cómo el alcance de la Constitución está condicionado por la interpretación de la ley ${ }^{71}$. En ella queda constancia de que el contenido de las normas constitucionales que debían servir de cánones de interpretación del decreto supremo impugnado, fue delimitado por la ley 19.300. Este caso ilustra cómo la

\footnotetext{
69 Requerimiento de inconstitucionalidad respecto del Decreto Supremo No 80, que "Establece la norma de emisión para molibdeno y sulfatos de efluentes descargados desde tranques de relaves al estero Carén" (2007).

70 Requerimiento de inconstitucionalidad respecto del Decreto Supremo No 80, que "Establece la norma de emisión para molibdeno y sulfatos de efluentes descargados desde tranques de relaves al estero Carén” (2007), cons. 13º. Aquí se ajusta perfectamente la regla de interpretación propuesta por ZAPATA (1990), p. 165: "Para definir el sentido de un concepto, el intérprete [de la Constitución] podrá, además, valerse de una definición legal calificada”.

71 Esta es precisamente la crítica de Aldunate al fallo: Aldunate (2009), pp. 468 y 469.
} 
interpretación de la ley es una operación prácticamente inevitable cuando se quiere juzgar la constitucionalidad de un decreto que la ejecuta.

Aunque podrían analizarse varias otras sentencias que refrendan lo dicho más arriba, quiero detenerme en la última que se ha dictado en la materia. Se trata de la sentencia rol 1849, de 12 de mayo de 2011, que acogió parcialmente el requerimiento de inconstitucionalidad dirigido contra el decreto supremo $N^{\circ}$ 264/2010 del Ministerio de Transporte y Telecomunicaciones ${ }^{72}$. Es instructivo seguir el argumento del Tribunal. En primer lugar afirma la doctrina dominante, porque declara que el control de constitucionalidad de decretos supremos consiste en "cotejar directa e inmediatamente las decisiones contenidas en el decreto impugnado con las normas constitucionales que se estiman vulneradas, para concluir, de tal confrontación, si existe o no algún vicio que ponga o pueda poner en contradicción este decreto con la Constitución Política"73. Por lo tanto, "no compete a este Tribunal pronunciarse sobre los posibles vicios de ilegalidad que, sin derivar en faltas de inconstitucionalidad, pudiere presentar el decreto cuestionado" 74 . En el considerando $8^{\circ}$ sintetiza el conflicto constitucional que debe resolver, que es doble: si la autoridad administrativa es competente para dictar un decreto como el impugnado, y si en el ejercicio de tales competencias la autoridad amaga derechos fundamentales. A la primera cuestión responde afirmativamente, porque el artículo 15 inc. final de la ley 18.168 autoriza al Ministro la concesión de permisos transitorios para usar el espectro radioeléctrico. "Desde la óptica constitucional, no cabe entonces cuestionar la competencia del Ejecutivo para expedir este tipo de permisos", más aún cuando habiendo sido el decreto tomado de razón por Contraloría, "goza de una presunción en orden a encontrarse plenamente ajustado al precepto citado de la Ley No 18.168 "75. Cierra el examen de la competencia contestando uno de los reproches de los requirentes, que fue la eventual incompatibilidad del decreto supremo $\mathrm{N}^{\circ} 264$ con la futura ley en la materia. Y contestó diciendo que "la validez del decreto supremo $\mathrm{N}^{\circ} 264$ no puede sino juzgarse en comparación con la legislación vigente a la fecha de su expedición"76. La supuesta afectación a los derechos fundamentales que supondría el decreto impugnado fue descartada por el Tribunal Constitucional subrayando en cada caso la legalidad de la actuación de la autoridad administrativa. Así, las garantías del artículo 19 Nos 12 y 22 no se ven afectadas, "pues ha quedado demostrado que el Ministerio de Transportes y Telecomunicaciones debe [actuar] (...) sobre la base del marco ya señalado por el legislador", y este marco es respetuoso de los principios de libertad e igualdad de acceso ${ }^{77}$.

72 Requerimiento de inconstitucionalidad respecto del Decreto Supremo $N^{\circ} 264$, que "Fija normas complementarias al Decreto No 136 de 14 de septiembre de 2009" (2011).

73 Requerimiento de inconstitucionalidad respecto del Decreto Supremo $N^{\circ} 264$, que "Fija normas complementarias al Decreto No 136 de 14 de septiembre de 2009" (2011), cons. 1.

74 Requerimiento de inconstitucionalidad respecto del Decreto Supremo $N^{\circ} 264$, que "Fija normas complementarias al Decreto No 136 de 14 de septiembre de 2009" (2011), cons. 2.

75 Requerimiento de inconstitucionalidad respecto del Decreto Supremo $N^{\circ} 264$, que "Fija normas complementarias al Decreto No 136 de 14 de septiembre de 2009" (2011), cons. 12.

76 Requerimiento de inconstitucionalidad respecto del Decreto Supremo $N^{\circ} 264$, que "Fija normas complementarias al Decreto $N^{o} 136$ de 14 de septiembre de 2009" (2011), cons. $18^{\circ}$.

77 Requerimiento de inconstitucionalidad respecto del Decreto Supremo $N^{\circ} 264$, que "Fija normas complementarias al Decreto No 136 de 14 de septiembre de 2009" (2011), cons. 33. 
Como se puede constatar en la sentencia rol 1849, la ley cumplió una función importante en la determinación de la constitucionalidad del decreto supremo. El decreto impugnado en este caso no fue inconstitucional, porque se ajustó al marco legal. La interpretación de la ley que entrañó la confrontación del decreto con su ley habilitante, resultó ser una operación determinante en la evaluación del cumplimiento de los estándares constitucionales del decreto. En pocas palabras, el juicio de constitucionalidad no prescindió de la interpretación de la ley, lo que significa que el alcance de la Constitución fue influido por la interpretación legal.

\section{El control de los decretos con fuerza de ley}

Los decretos con fuerza de ley deben cumplir con una condición básica para ser constitucionales. Esta condición es que sean conformes con la ley delegatoria. Si el Presidente de la República dicta el decreto con fuerza de ley excediéndose del marco autorizado por el Congreso, el acto es simultáneamente ilegal e inconstitucional. Por esta razón, el análisis de la jurisprudencia del Tribunal Constitucional que ha resultado del control de constitucionalidad de los decretos con fuerza de ley, es interesante en este trabajo.

Las sentencias que el Tribunal Constitucional ha dictado en esta materia son solo tres $^{78}$. En la primera de ellas, de 1971, declaró la inconstitucionalidad del decreto con fuerza de ley $\mathrm{N}^{\circ} 1 / 1971$, por haber sido dictado fuera del plazo de seis meses concedido por la ley delegatoria ${ }^{79}$. La circunstancia de haber sido remitido el texto del decreto con fuerza de ley dentro del plazo a Contraloría para su toma de razón no puede alegarse, si es que el texto es luego retirado por el propio Presidente antes del pronunciamiento del órgano contralor. En el considerando $10^{\circ}$ resumió el argumento: "Que de lo expuesto resulta que si retirado el acto emitido se cumple durante el retiro el plazo de la ley delegatoria, el nuevo texto dictado por el Presidente de la República adolece de inconstitucionalidad porque una vez vencido el plazo legal, el Presidente actúa sin la autorización que la Carta Fundamental establece, y, por lo tanto, la infringe". Interesa destacar la identificación que se hace entre actuar una vez vencido el plazo y actuar sin la autorización que la Carta Fundamental establece; en otras palabras, la identificación entre la ilegalidad y la inconstitucionalidad. El Tribunal Constitucional hubo de constatar que el Presidente no cumplió con la ley para decidir que su actuar fue inconstitucional.

La sentencia rol 392, 393 y 394 (acumulados) es la más interesante en el contexto de este trabajo ${ }^{80}$. En ella el Tribunal Constitucional hubo de resolver sobre la constitucionalidad del decreto con fuerza de ley N²1/2003 del Ministerio de Hacienda, que fijó una

\footnotetext{
${ }^{78}$ La segunda sentencia es harto peculiar, porque recayó sobre un decreto con fuerza de ley dictado al amparo de la ley $N^{\circ} 16.744$ (1968). Dado que la Constitución de 1980 estableció un año como plazo máximo para delegar facultades legislativas, la habilitación indefinida del artículo 2 inc. final de la ley $\mathrm{N}^{\circ} 16.744$ en favor del Presidente de la República para decidir la incorporación de trabajadores independientes al régimen de seguro social no tiene ningún valor. Luego, es un decreto con fuerza de ley que técnicamente carece de ley delegatoria. Por esto digo que es una sentencia peculiar: no es posible confrontar el decreto con fuerza de ley con ley alguna, porque no hay ley.

79 Requerimiento de inconstitucionalidad respecto del DFL $N^{\circ} 1^{\circ}$ de 1971 (1972).

${ }^{80}$ Requerimiento de inconstitucionalidad respecto del Decreto con Fuerza de Ley No 21, de 2003, del Ministerio de Hacienda (2003).
} 
nueva integración del directorio de la Empresa Nacional de Minería. Como era de prever, los reproches de inconstitucionalidad que los parlamentarios requirentes hicieron al decreto con fuerza de ley consistieron en diversas formas de exceso del marco fijado por la ley delegatoria. En este caso particular, el Tribunal Constitucional se propuso resolver como una cuestión previa al fondo la de "si la extralimitación del Presidente de la República, en el ejercicio de la potestad delegada, origina solo un problema de ilegalidad o, también, suscita uno de inconstitucionalidad" ${ }^{21}$. Esto porque Contraloría objetó la competencia del Tribunal, alegando que las inconsistencias del decreto con su ley delegatoria eran vicios de legalidad ${ }^{82}$. En el considerando 90 resolvió el punto: "es de absoluta nitidez que si la Norma Fundamental exige que la ley delegatoria señale las materias precisas sobre las que recae la delegación, es porque esta delegación solo autoriza al Presidente de la República para actuar dentro de los límites determinados en la autorización correspondiente y, al sobrepasarlos, es notorio que está contraviniendo la prohibición contenida en el precepto en comento [artículo 61 de la Constitución], así como, en el artículo 60 de la Carta Fundamental y que, en consecuencia, adolece de inconstitucionalidad el respectivo decreto con fuerza de ley. Por otro lado, es igualmente notorio que si en el decreto con fuerza de ley se sobrepasan los límites establecidos por el Poder Legislador, no solo se está invadiendo el campo de la reserva legal, sino que, además, se infringe el artículo $7^{\circ}$ de la Carta Fundamental, desde que ese acto jurídico ha sido expedido por el Presidente de la República fuera del ámbito de su competencia, lo que lo hace, también, inconstitucional".

Quiero llamar especialmente la atención sobre el uso que el Tribunal hace del adverbio también en el considerando $1^{\circ}$ de la sentencia rol 392, 393 y 394 (acumulados): "si la extralimitación del Presidente de la República, en el ejercicio de la potestad delegada, origina solo un problema de ilegalidad o, también, suscita uno de inconstitucionalidad". El Tribunal no establece una alternativa sobre la naturaleza de la extralimitación; no se pregunta si acaso es ilegal o inconstitucional. En cambio, se pregunta si además de ser ilegal no será también inconstitucional. Y en el considerando $9{ }^{\circ}$ responde que sí. En otras palabras, está reconociendo una identificación entre ilegalidad e inconstitucionalidad ${ }^{83}$. Esto significa que para juzgar la constitucionalidad de los decreto con fuerza de ley es indispensable confrontar el acto con la ley delegatoria, lo cual supone interpretar la ley. Luego, la interpretación de la ley influye decisivamente en los alcances de la Constitución como canon de interpretación.

\footnotetext{
${ }_{81}$ Requerimiento de inconstitucionalidad respecto del Decreto con Fuerza de Ley No 21, de 2003, del Ministerio de Hacienda (2003), cons. 10.

82 Dictamen 47.681, de 23 de octubre de 2003. Esta es la tesis de Verdugo et al. (1997), p. 247 y Zúniga (2002), p. 89.

83 Ribera (2004), p. 141 habla de inconstitucionalidad indirecta cuando el vicio de la norma consiste en transgredir "el marco delegatorio que autoriza su existencia". Lo mismo Henríquez (2010), p. 159. CAzOR (2002), p. 113 también suscribe la tesis: en el caso de los decreto con fuerza de ley disconformes con la ley habilitante, ilegalidad e inconstitucionalidad son vicios concurrentes. Los ministros Bertelsen y Venegas repitieron este criterio en su voto disidente en la sentencia Proyecto que modifica la Ley No 17.997 Orgánica Constitucional del Tribunal Constitucional (2009), cons. $3^{\circ}$. Acerca de la superposición de la legalidad y la constitucionalidad en un contexto más amplio (RuIZ-RiCO, 1997, pp. 21-22; LuCAS, 1997, pp. 131-132).
} 


\section{LA DIMENSIÓN LEGAL DE LA INTERPRETACIÓN CONSTITUCIONAL}

En los apartados anteriores se ha intentado ofrecer un contraste entre teoría y práctica, en el marco de una específica expresión del principio de supremacía constitucional que es el principio de interpretación conforme. Por una parte, se sostiene que la supremacía constitucional significa que la Constitución es el canon de interpretación de la ley (apartado II y III) y, por otra, la jurisprudencia del Tribunal Constitucional muestra que la ley incide decisivamente en la determinación de los contenidos de la Constitución (apartado IV). Aunque podría discutirse el carácter de esta incompatibilidad (si más o menos aparente; si más o menos absoluta), lo cierto es que la diferencia detectable entre estos dos enfoques demanda, por lo menos, una explicación. Esto es lo que se ofrece a continuación.

\section{A. La delimitación legal de las garantías CONSTitucionales}

Está previsto en la Constitución que los contenidos de las garantías del artículo 19 sean delimitados por la ley. Los motivos para afirmar esto son varios. En primer lugar, las múltiples referencias que el texto del artículo 19 hace a la ley como fuente de los casos, formas y condiciones de ejercicio de los derechos fundamentales. En segundo lugar, la reserva de las garantías constitucionales al legislador (artículo 64 en relación al artículo 63 de la Constitución). En tercer lugar, el texto del artículo $19 \mathrm{~N}^{\circ} 26$, que reconoce a la ley la función de regular, complementar y limitar las garantías constitucionales.

La delimitación legal del contenido de las garantías constitucionales significa que la ley es una fuente para conocer el alcance de los derechos garantizados por la Constitución ${ }^{84}$. Así, por ejemplo, la ley 19.733 (Ley de Prensa) es indispensable para precisar el contenido de la libertad de información; la ley 19.638 (Ley de Culto) es necesaria para conocer los alcances de la libertad de culto; el DL No 830 (Código Tributario) precisa los términos del derecho a la igualdad tributaria; la ley 19.628 (Ley sobre Protección de la Vida Privada) caracteriza el derecho a la vida privada. Los ejemplos podrían multiplicarse ${ }^{85}$.

No se está diciendo que la ley agote el significado de la garantía constitucional que regula, complementa o limita. Lo que se quiere decir es que, allí donde la ley ha precisado el significado de una garantía constitucional, la garantía constitucional no puede interpretarse al margen de la ley ${ }^{86}$. Esta consecuencia debe entenderse como una exigencia de la supremacía constitucional, en la medida que es la propia Constitución la que delega en la

\footnotetext{
${ }^{84}$ El legislador es un intérprete de la Constitución (Zapata, 2008, p. 244; Nogueira, 2006, p. 128).

85 Silva (1997), p. 157, afirma la importancia de esta legislación como fuente de interpretación de la Constitución.

86 Por supuesto que esta consecuencia no es válida siempre, porque si lo fuera no tendría cabida la declaración de inconstitucionalidad de una ley por razones de fondo. Sin embargo, vale para la generalidad de los casos y armoniza bien con lo excepcional que es la declaración de inconstitucionalidad de la ley (medida de ultima ratio, ha dicho el Tribunal Constitucional, Requerimiento de inconstitucionalidad respecto del texto integro del artículo 595 del Código Orgánico de Tribunales (2009), cons. 21\%). Zapata reconoce la ambigüedad del valor que la interpretación legislativa de la Constitución tiene para el Tribunal Constitucional: no lo vincula pero merece una respetuosa consideración. ZAPATA (2008), p. 246.
} 
ley la determinación de las formas, casos y condiciones de ejercicio de los derechos garantizados por el artículo $19^{87}$.

Aquí también resulta oportuno referirse a la interpretación judicial de la ley, en cuanto que afecta la interpretación de la Constitución. En efecto, la jurisdicción ordinaria no está en un plano absolutamente independiente de la jurisdicción constitucional; la interpretación judicial de la ley incide en la interpretación de la Constitución, también cuando se trata de juzgar la constitucionalidad de la ley. Lo que trato de decir lo dijo el Tribunal Constitucional español en 1984: "no puede prescindir la jurisdicción constitucional del análisis crítico de la aplicación que la jurisdicción ordinaria hace de la Ley cuando tal análisis es necesario para determinar si se ha vulnerado o no alguno de los derechos fundamentales o libertades públicas cuya salvaguarda le esté encomendada" ${ }^{88}$. Este aspecto es especialmente pertinente en el ámbito de la inaplicabilidad, considerando la frecuencia con que los requerimientos se dirigen contra una determinada interpretación judicial de la ley ${ }^{89}$.

\section{B. LA NECESIDAD DE LAS LEYES COMPLEMENTARIAS}

La finalidad propia de la Constitución requiere que su texto sea flexible. De allí que en su redacción se prefiera una extensión relativamente corta y se utilicen términos más o menos amplios en su redacción. La finalidad de la Constitución también explica otra característica típica de esta norma, que es su jerarquía suprema. Luego, la forma que tiene el texto de la Constitución es inseparable de su carácter supremo, porque ambos elementos se ordenan al cumplimiento de la finalidad específica de la Constitución. Esto establece una relación entre la peculiaridad del texto y la supremacía, en la que esta depende en cierto modo de aquella. Esto lleva a que la realización del fin que justifica la existencia de la Constitución esté sujeta -como condición necesaria, aunque no suficiente- de que se respeta la elasticidad de su texto, conservándolo libre de una precisión y desarrollo que lo anquilosaría. Y precisamente se cumple esto último dejando al legislador la tarea de ofrecer, al amparo de la Constitución, una regulación acabada de los supuestos que se contienen más o menos esbozados en el texto constitucional (si es que no lo están solo en forma tácita).

La existencia de leyes que precisen el contenido de las garantías constitucionales, es necesaria para que la Constitución permanezca fiel a su finalidad. Si la Constitución "descendiera” a cumplir la función que las leyes tienen encomendadas, no solo abandonaría su vocación trastrocando el orden del sistema, sino que serviría deficientemente a los fines propios de la ley, porque no está diseñada para ellos.

Podría decirse que la Constitución es apta para cumplir su función, en la medida que hay una regulación que satisface la necesidad de dar respuesta a los problemas más o menos complejos del Derecho. Esta regulación descansa principalmente en la ley, es decir,

\footnotetext{
87 Aldunate (2002), pp. 261-270, menciona una serie de elementos que servirían para evaluar la interpretación de la Constitución, a fin de acotar la discrecionalidad de los jueces. En este contexto, ¿̇no podría sugerirse que también las leyes sirvieran como pautas para evaluar el sentido que los jueces asignen a las expresiones normativas de la Constitución, cumpliendo la tarea de acotar la discrecionalidad judicial?

88 Sentencia 50/1984, de 5 de abril de 1984 , cons. $3^{\circ}$.

89 Jiménez (1995), p. 78 alude al efecto condicionante que la interpretación judicial de la ley y de la Constitución puede tener en el juicio de constitucionalidad de la ley que hace el Tribunal Constitucional.
} 
la ley es un elemento clave para asegurar el correcto funcionamiento de la Constitución ${ }^{90}$. Esto es lo mismo que reconocer la importancia de la ley para conservar las características de la Constitución ${ }^{91}$. En consecuencia se podría afirmar que la ley cumple de manera indirecta la función de garantizar la supremacía constitucional ${ }^{92}$.

\section{El RANGo de legítima autonomía del LEgislador}

La convivencia equilibrada entre los poderes del Estado implica la garantía de unos ámbitos de autonomía propios para cada poder. En el caso del poder legislativo, se comprende dentro del ámbito de su autonomía la regulación, complemento y limitación de los derechos garantizados por el artículo $19^{93}$. El reconocimiento legal de las garantías constitucionales, con el mayor grado de precisión e inflexibilidad que este implica respecto de su formulación constitucional, es un resultado buscado por la Constitución, en la medida que contribuye al sostenimiento del equilibrio de los poderes ${ }^{94}$.

El diseño constitucional cuenta con el Poder Legislativo para regular los derechos, pero le pone límites. Los límites son, en cada caso, fijados por el órgano de control que debe juzgar si en el ejercicio de su atribución el Poder Legislativo se excedió. El hecho de que la ubicación exacta de los límites sea una cuestión que se determine en cada caso, no debe llevar a pensar que la autonomía del legislador es un ámbito virtualmente entregado a la voluntad del órgano de control. Ese ámbito de autonomía existe realmente ${ }^{95}$.

La autonomía que tiene el Congreso para delimitar el contenido de las garantías constitucionales, significa que sus decisiones en la materia deben ser reconocidas por los demás poderes y órganos de control mientras respeten los límites fijados por la Constitución. Luego, la determinación del contenido de las garantías constitucionales no puede hacerse al margen de las definiciones legislativas correspondientes, porque así lo exige la

\footnotetext{
90 En este sentido entiendo a Balaguer (1997), p. 43, cuando afirma que separar la hermenéutica constitucional de la hermenéutica del ordenamiento infraconstitucional, puede afectar la normatividad de la Constitución. A una conclusión parecida llega Orrego (2002), p. 474 a propósito de la aplicación directa de la Constitución: este principio perjudica su condición suprema.

${ }_{91}$ Este presupuesto debilita la crítica que DA SiLVA (2004), p. 22, hace a la doctrina de la deferencia hacia el legislador. Porque si bien es cierto, como dice él, que tal doctrina es una máscara que oculta las correcciones que el Tribunal hace a la obra del legislador al interpretarla, también es cierto que lo hace dentro del campo semántico habilitado por los términos fijados por el legislador.

92 Este presupuesto explica que las sentencias sobre derechos fundamentales (v.gr. recurso de protección; inaplicabilidad) recurran a la ley y a sus criterios de interpretación en la parte considerativa. Una crítica a este modo de argumentar (y, por lo tanto, a este presupuesto), en CONTESSE (2011), p. 285.

93 Zapata (2008), p. 233.

94 La referencia al principio de separación de los poderes como un límite al arbitrio del Tribunal Constitucional (Espinosa-Saldaña, 2006, p. 213; Nogueira, 2009, pp. 170-173) es una forma de aludir a la dimensión legal de la Constitución. Otra fórmula análoga es la de la dignidad democrática de la ley: Ferreres (2007), p. 39, y el voto de minoría de los Ministros Viera-Gallo y Carmona, en la sentencia Paúl Latorre (2010), cons. 10.

95 Tomás y VAliente (1995), pp. 32 y 33. Zapata (2008), p. 234: "Las consideraciones técnicas, políticas o económicas, en base a las cuales el legislador escoge una u otra fórmula, en la medida -por supuesto- que no infrinjan la Constitución, se encuentran más allá del control jurídico del TCCh [Tribunal Constitucional]”.
} 
Constitución. En otras palabras, el respeto de la supremacía constitucional implica atenerse a las leyes para interpretar el contenido de las garantías constitucionales ${ }^{96}$.

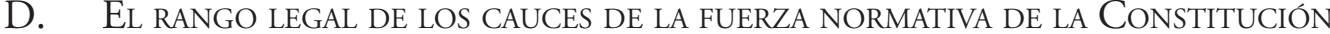

La Constitución "presupone la existencia de un proceso como garantía de la persona humana, [pero es] la ley, en el desenvolvimiento normativo jerárquico de preceptos [la que] debe instituir ese proceso" 97 . Esto significa que las formas de hacer valer los derechos garantizados por la Constitución se concretan en la legislación y, en consecuencia, la eficacia de la Constitución resulta mediatizada por las disposiciones legales de procedimiento.

La eficacia normativa de la Constitución está finalmente condicionada por los medios procesales para hacerla valer en tribunales ${ }^{98}$. La mayoría de los mecanismos que típicamente se caracterizan por hacer efectiva la Constitución, están regulados por las leyes. A veces se trata de una legislación que desarrolla mecanismos de protección expresamente contenidos en la Constitución, como en el caso de la inaplicabilidad o el habeas corpus $^{99}$; a veces, en cambio, se trata de leyes que crean mecanismos nuevos, como el amparo económico o la tutela laboral ${ }^{100}$.

La naturaleza legal de los mecanismos que garantizan la eficacia normativa de la Constitución significa que esta queda sujeta a los términos de la ley. Aunque se trate de disposiciones legales de contenido esencial o principalmente procedimental, la eficacia de la Constitución es de todos modos mediada por la ley. Por otra parte, sería ingenuo pensar que el carácter esencialmente procesal de las normas que regulan la tramitación de tales mecanismos de protección deja intacto el contenido de los derechos fundamentales en juego. En realidad, todas las normas procesales, por inocuas que parezcan, actúan como cauces de la eficacia normativa de la Constitución, modulando su fuerza y alcance. Un ejemplo para ilustrar lo que trato de decir es el artículo 84 de la ley orgánica del Tribunal Constitucional, que define las causales de inadmisibilidad de los requerimientos de inaplicabilidad. Estas causales de naturaleza legal actúan como esclusas de la fuerza normativa de la Constitución, acotando el margen que permitiría una interpretación directa del artículo 93 inc. $11^{\circ}$ de la Constitución.

96 La doctrina de la deferencia razonada podría explicarse desde este punto de vista. Pero el término deferencia resultaría inadecuado como sinónimo de condescendencia, porque es la idea misma de supremacía constitucional la que exige el cumplimiento de esta condición por parte del órgano jurisdiccional. Contrariamente a este planteamiento, Aldunate (2009), p. 446, sugiere la incompatibilidad de la deferencia razonada con la idea de fuerza normativa de la Constitución, porque no ve que la restricción del control que ejerce el Tribunal Constitucional sobre el legislador sea una exigencia intrínseca a la fuerza normativa.

97 Couture (2010), p. 122. Recientemente, en el mismo sentido, BBVA (2013).

98 Fernández (2001), p. 85.

99 La inaplicabilidad se halla en la ley No 17.997 (1981), arts. 79 a 92; y el habeas corpus en el Código Procesal Penal (art. 95) y en el Código de Procedimiento Penal (arts. 306 a 317 bis).

100 El amparo económico fue creado por la ley $N^{\circ} 18.971$ (1990) y la tutela laboral se halla en el Código del Trabajo (arts. 485 a 495). 
E. La mutua DePENDENCIA QUE NeCESARIAMENTE EXISTE ENTRE LOS TÉRMINOS DE UNA COMPARACIÓN

El control de constitucionalidad consiste en una comparación entre dos normas: la Constitución y otra norma inferior cualquiera. El juicio de constitucionalidad expresa el resultado de esa comparación, declarando la in/compatibilidad de la norma juzgada. Si la norma inferior es compatible con la Constitución, es constitucional; si es incompatible, inconstitucional. Sin embargo, esta operación no puede entenderse como si solo uno de los términos de la comparación -la norma infraconstitucional- fuera interpretado en función del otro, que mientras tanto permanece estático en su significado. Cualquier comparación implica siempre un juicio sobre los dos términos de la misma.

La sentencia que declara el resultado del control de constitucionalidad, no está declarando solo el sentido de la norma controlada, sino también el de la norma de control. Si al comparar una norma con la Constitución se llega a la conclusión de que la norma es in/ constitucional, al mismo tiempo se está declarando el sentido de la Constitución que determinó el resultado de la comparación. "Al definir a la Constitución como parámetro para saber cómo debe interpretarse la ley, no se puede evitar de interpretar, aunque sea en forma mínima, a la propia Constitución" ${ }^{101}$.

Cada acto en que se controla la constitucionalidad de la ley requiere una interpretación de la Constitución. Pero como también requiere una interpretación de la ley, resulta que las operaciones de interpretar la ley e interpretar la Constitución convergen en un mismo acto. El control de constitucionalidad implica, simultáneamente, una interpretación de la norma de control y de la norma controlada. Pero, además, la interpretación de una y otra norma está recíprocamente influenciada. Como en todo proceso interpretativo, en el control de constitucionalidad se verifica un "círculo hermenéutico" entre la Constitución y la norma ${ }^{102}$. El significado de la Constitución es parcialmente iluminado por la norma sometida a control, la que a su vez resulta iluminada por la Constitución. Este influjo mutuo se repite en un "ir y venir" que va progresivamente aclarando el sentido de los textos que se reclaman mutuamente. La Constitución adquiere un sentido útil para el acto de control, solo una vez que es puesta en contacto con la norma a controlar. Antes o después de ese momento, la Constitución permanece encerrada en su número potencialmente indefinido de sentidos.

Existe una mutua dependencia entre la Constitución y la ley, en cuanto se influyen recíprocamente en la determinación de su contenido normativo. Es la dependencia propia de los dos términos de cualquier comparación. En este contexto, puede afirmarse que la ley es fuente de interpretación de la Constitución. En otras palabras, que el sentido de la Constitución depende de la ley, al menos parcialmente. El Tribunal Constitucional no pue-

101 Da Silva (2005), p. 4. Díaz (2011), p. 41, parafraseando a Crisafulli: "resulta imprescindible [que las sentencias de la Corte Constitucional] realicen una interpretación, tanto del precepto legal impugnado, como de la Constitución que sirve de parámetro del enjuiciamiento”. En el mismo sentido, Jiménez (1997), p. 98. Gómez (2005), p. 679: "La labor de interpretar la Constitución, de cara al control constitucional, presupone juzgar la ley y las valoraciones que el legislador adopta normativamente". Veo este mismo reconocimiento, aunque implícito, en ZapATA (2008), p. 324.

102 Larenz (2001), pp. 194-200. 
de evitar esta dependencia, y pretenderlo no solo sería vano sino también nocivo, porque oscurecería una fuente importante de interpretación de la Constitución.

\section{CONCLUSIÓN}

Por una parte, la teoría del control de constitucionalidad enseña que la Constitución sirve como canon de interpretación al mismo tiempo que se construye como tal. Por otra parte, la práctica del control de constitucionalidad por el Tribunal Constitucional, muestra que la ley es un factor que determina en un grado importante el sentido y alcance de la Constitución en cada caso. Esta situación parece, a primera vista, contradecir los presupuestos de la supremacía constitucional, porque estaría postulando una dinámica entre la ley y la Constitución ajena al principio de jerarquía normativa, y colocando en entredicho la directa aplicabilidad de la norma constitucional. Sin embargo, esto no es así. La incidencia que la ley tiene en la actualización del sentido de la Constitución debe entenderse, normalmente, como una exigencia de la supremacía constitucional.

La jurisprudencia del Tribunal Constitucional prueba que, normalmente, no puede prescindirse de la ley en la construcción del parámetro de control de constitucionalidad. Esto es lo mismo que decir que la Constitución tiene una dimensión legal. En el contexto de este trabajo, la dimensión legal de la Constitución significa que la ley acota los potenciales sentidos de la norma constitucional; la ley orienta la actividad interpretativa de la Constitución, prestándole incluso sus palabras a veces. Esta dimensión legal de la Constitución no debe entenderse como un defecto accidental de la supremacía constitucional, como si la cosa pudiera evitarse o debiera superarse. La dimensión legal de la Constitución es un aspecto de la supremacía constitucional que enriquece el contenido de este principio sin debilitarlo. Eso sí, implica matizar algunas facetas de su formulación.

\section{BIBLIOGRAFÍA CITADA}

Aldunate, Eduardo (1994): "Interpretación Constitucional y Decisión Política”, en: Revista de Derecho, Universidad Católica de Valparaíso, Nº XV, pp. 31-66;

Aldunate, Eduardo (1998): “Categorías para el análisis de la argumentación jurídica del Tribunal Constitucional. Los argumentos sobre la base del tenor literal y la interpretación armónica”, en: Revista Chilena de Derecho, número especial, pp.115-120;

Aldunate, Eduardo (2000): "La doctrina nacional sobre interpretación constitucional. Estado y crítica", en: Revista de Derecho, Universidad de Antofagasta, Nº8, pp. 59-74;

Aldunate, Eduardo (2002): "Reformulación de las reglas o elementos de interpretación para una práctica de la interpretación constitucional”, en: Revista de Derecho, Universidad de Piura, volumen 3, pp. 259-273;

Aldunate, Eduardo (2009): "La fuerza normativa de la Constitución y el sistema de fuentes del Derecho", en: Revista Chilena de Derecho, vol. XXXII, pp. 443-484;

Balaguer, María Luis (1997): Interpretación de la Constitución y ordenamiento jurídico (Madrid, Tecnos) 182 pp.;

Bordalí, Andrés (2009): "Jueces constitucionales. Un poder incómodo", en: Nogueira, Humberto (coord.), La ciencia del Derecho Procesal Constitucional (Santiago, Librotecnia) pp. 47-71; 
Cazor, Kamel (2002): La sumisión a derecho de los actos y disposiciones del Presidente de la República (Tomo II, Santiago, Universidad Central de Chile, Facultad de Ciencias Jurídicas y Sociales) 337 pp.

CEA, José Luis (1984): "Hermenéutica constitucional, soberanía legal y discrecionalidad administrativa”, en: Revista Chilena de Derecho, vol. XI, pp. 7-16.

Cea, Egaña, José Luis, "Proyecciones de la Separación de Poderes en el Estado Contemporáneo”, en: CEA, José Luis (edit.), Escritos de Justicia Constitucional, Cuadernos del Tribunal Constitucional Número 35 (Santiago, LOM Ediciones) pp. 23-38.

CONTESSE, Jorge (2011): "Responsabilidad por la interpretación constitucional”, en: Revista Derecho y Humanidades, N 11, pp. 281-293.

Couture, Eduardo (2010): Fundamentos del derecho procesal civil (Buenos Aires, Euros Editores, $4^{\mathrm{a}}$ edición) $424 \mathrm{pp}$.

Da Silva, Virgilio Alfonso (2005): "La interpretación conforme a la Constitución. Entre la trivialidad y la centralización judicial" [fecha de consulta: 20 de mayo de 2013]. Disponible en http://www.juridicas.unam.mx/publica/rev/cconst/cont/12/ard/ard1.htm

DíAz, Javier (2011): Las sentencias interpretativas del Tribunal Constitucional (México, Editorial Porrúa) 376 pp.

Domínguez, Ramón (1196): "Aspectos de la constitucionalización del derecho civil chileno”, en: Revista de Derecho y Jurisprudencia, Tomo XCIII, N 3, pp. 107-137.

Ducci, Carlos (1977), Interpretación jurídica: en general y en la dogmática chilena (Chile, Editorial Jurídica de Chile) 266 pp.

ESPINOSA-SALDAÑA, Eloy (2006): "Sentencias interpretativas: sus alcances y algunas reflexiones sobre su uso a la luz de la experiencia peruana”, en: Estudios Constitucionales, Año $4 \mathrm{~N}^{\circ} 2$, pp. 203-220.

Fernández, Miguel Ángel (2001) "La fuerza normativa de la Constitución”, en: Revista de Derecho Público, vol. 63, 2001, t. I, pp. 77-102.

Ferreres, Víctor (2007): Justicia constitucional y democracia (Madrid, Centro de Estudios Políticos y Constitucionales, 2a edición) 278 pp.

García de Enterría, Eduardo (1983): La Constitución como norma y el Tribunal Constitucional (Madrid, Civitas, $3^{a}$ edición, 2001).

Gómez, Gastón (2005): "La reforma constitucional a la jurisdicción constitucional. El nuevo Tribunal Constitucional chileno”, en: ZúñIga, Francisco (coord.) Reforma Constitucional (Santiago, LexisNexis) pp. 651-684.

Henríquez, Miriam (2010): "El control de constitucionalidad de los decretos con fuerza de ley en la Ley Orgánica del Tribunal Constitucional”, en: Nogueira, Humberto (coord.) Temas de Derecho Procesal Constitucional. Reflexiones jurídicas sobre competencias del Tribunal Constitucional y la nueva LOC del Tribunal Constitucional (Santiago, Librotecnia) pp. 147-160.

JimÉnEZ, Javier (1995): Consideraciones sobre el control de constitucionalidad de la ley en el Derecho Español, en: Rodríguez-Piñero, Miguel et al.: La jurisdicción constitucional en España (Madrid, Centro de Estudios Constitucionales) pp. 71-112.

JimÉnEZ, Javier (1997): "Algunos rasgos de la cuestión de inconstitucionalidad en España”, en: Ruiz-Rico, Gerardo (edit.) La aplicación jurisdiccional de la Constitución (Valen- 
cia, Consejo General del Poder Judicial-Universidad de Jaén-Tirant lo Blanch) pp. 83109.

LAREnZ, Karl (2201): Metodología de la ciencia del derecho (Traducc. Marcelino RodríGUEZ, Barcelona, Ariel, 2a ed.) 536 pp.

LuCAS, Pablo (1997): "El amparo judicial de los derechos fundamentales”, en: RuIz-Rico, Gerardo (edit.) La aplicación jurisdiccional de la Constitución (Valencia, Consejo General del Poder Judicial-Universidad de Jaén-Tirant lo Blanch) pp. 113-149.

Navarro, Enrique (1992): "Mecanismos de interpretación establecidos en la Constitución de 1980”, en: Interpretación, integración y razonamiento jurídicos. Conferencias y ponencias presentadas en el Congreso realizado en Santiago y Viña del Mar entre el 23 y 25 de mayo de 1991 (Santiago, Universidad de Chile y Universidad Adolfo Ibáñez) pp. 304-326.

Nogueira, Humberto (2006): Lineamientos de interpretación constitucional y del bloque constitucional de derechos (Santiago, Librotecnia) $413 \mathrm{pp}$.

Nogueira, Humberto (2009): "Enfoque sobre interpretación constitucional y jurisdicción constitucional”, en: Temas actuales de Derecho Constitucional (Santiago, Asociación Chilena de Derecho Constitucional, Editorial Jurídica de Chile) pp. 155-186.

Orrego, Cristóbal (2002): "La cultura jurídica interna: ¿hacia el colapso de la pirámide?, en: Anuario de filosofía jurídica y social, No 20, pp. 461-478.

Pfeffer, Emilio (1999): "Análisis de los criterios interpretativos del Tribunal Constitucional en Chile (periodo 1981-1990)", en: La jurisdicción constitucional chilena ante la reforma, Cuadernos de Análisis Jurídico, № 41 (Santiago, Universidad Diego Portales) pp. 109-117.

Ribera, Teodoro (2004): "El control de constitucionalidad de los decretos con fuerza de ley por el Tribunal Constitucional”, en: Revista de Derecho Público, Vol. 66, pp. 121-145.

RiberA, Teodoro (1989): "El Tribunal Constitucional y su aporte al desarrollo del Derecho. Aspectos relevantes de sus primeros 59 fallos”, en: Estudios Públicos N 34, pp. 195-228.

Ríos, Lautaro (2002): "El control difuso de constitucionalidad de la ley en la República de Chile" [fecha de consulta: 20 de mayo de 2013]. Disponible en: http://www.scielo.cl/ scielo.php?pid=S0718-00122002000100021\&script=sci_arttext

Rodríguez, Pablo (1990): teoría de la interpretación jurídica (Santiago, s.e.) 209 pp.

Ruiz-Rico, Gerardo (1997): "Algunas reflexiones sobre la convergencia funcional-disfuncional del Tribunal Constitucional y el Poder Judicial en la aplicación jurisdiccional de la Constitución", en: Ruiz-Rico, Gerardo (edit.) La aplicación jurisdiccional de la Constitución (Valencia, Consejo General del Poder Judicial-Universidad de Jaén-Tirant lo Blanch) pp. 14-26.

Silva, Alejandro (1997): Tratado de Derecho Constitucional (Tomo I, Santiago, Editorial Jurídica de Chile, 2a edición) 322 pp.

SiLVA, Luis Alejandro (2009): El control de constitucionalidad de los actos administrativos legales (Santiago, LegalPublishing) 308 pp.

SiLva, Luis Alejandro (2012): “¿Es el Tribunal Constitucional el supremo intérprete de la Constitución” [fecha de consulta: 20 de mayo de 2013]. Disponible en http://www.scielo.cl/scielo.php?pid=S0718-68512012000100014\&script=sci_arttext 
Sото Kloss, Eduardo (1996): Derecho Administrativo: Bases Fundamentales (Tomo II, Santiago, Editorial Jurídica de Chile) 480 pp.

Tomás y Valiente, Francisco (1995): La Constitución y el Tribunal Constitucional, en: Rodríguez-Piñero, Miguel et al:: La jurisdicción constitucional en España (Madrid, Centro de Estudios Constitucionales) pp. 15-34.

Valenzuela, Eugenio: Criterios de hermenéutica constitucional aplicados por el Tribunal Constitucional, en: Cuadernos del Tribunal Constitucional No 31 (Santiago, 2006) 125pp.

Verdugo, Mario, Pfeffer, Emilio y Nogueira, Humberto (1994): Derecho Constitucional (Tomo I, Santiago, Editorial Jurídica de Chile) 415 pp.

Zapata, Patricio (1990): "La Interpretación de la Constitución", en: Revista Chilena de Derecho, volumen 17, No 1, pp. 161-177.

Zapata, Patricio (2008): Justicia Constitucional: teoría y práctica en el derecho chileno y comparado (Santiago, Editorial Jurídica de Chile) 623 pp.

ZúNiga, Francisco (2002): Elementos de jurisdicción constitucional (Tomo II, Santiago, Facultad de Ciencias Jurídicas y Sociales Universidad Central de Chile) 279 pp.

ZúNIga, Francisco (2005): “Control de constitucionalidad y casación”, en: Estudios Constitucionales, Año $3 \mathrm{~N}^{\circ} 2$, pp. 15-27.

\section{NORMAS CITADAS}

Ley N ${ }^{\circ}$ 1.552, Código de Procedimiento Civil, Diario Oficial, 20 de agosto de 1902;

Ley $N^{\circ}$ 1.853, Código de Procedimiento Penal, Diario Oficial, 19 de febrero de 1906;

Decreto Supremo No 2.226, Código de Justicia Militar, Diario Oficial, 19 de diciembre de 1944;

Decreto con Fuerza de ley $\mathrm{N}^{\circ} 292$, aprueba la ley orgánica de la dirección general del territorio marítimo y de marina mercante, Diario Oficial, 5 de agosto de 1953;

Ley $\mathrm{N}^{\circ} 16.744$, establece normas sobre accidentes del trabajo y enfermedades profesionales, Diario Oficial, 1 de febrero de 1968;

Decreto Ley No 824, Ley sobre Impuesto a la Renta, Diario Oficial, 31 de septiembre de 1974; Ley 17.997, ley orgánica del Tribunal Constitucional, Diario Oficial, 19 de mayo de 1981; Ley $\mathrm{N}^{\circ}$ 18.971, establece recurso especial que indica, Diario Oficial, 10 de marzo de 1990; Ley $\mathrm{N}^{\circ}$ 19.300, sobre bases generales del medio ambiente, Diario Oficial, 9 de marzo de 1994; Decreto con Fuerza de Ley $\mathrm{N}^{\circ}$ 1, Código Civil, Diario Oficial, 30 de mayo de 2000;

Ley No 19.696, Código Procesal Penal, Diario Oficial, 12 de octubre de 2000;

Ley $\mathrm{N}^{\circ} 19.733$, ley sobre las libertades de opinión e información y ejercicio del periodismo, Diario Oficial, 4 de junio de 2001;

Decreto con Fuerza de Ley $N^{\circ}$ 1, Código del Trabajo, Diario Oficial, 16 de enero de 2003;

Decreto Supremo No 100, Constitución Política de la República de Chile, Diario Oficial, 22 de septiembre de 2005;

Decreto con Fuerza de Ley $\mathrm{N}^{\circ}$ 1, fija el texto refundido, coordinado y sistematizado de la ley $n^{\circ}$ 18.695, orgánica constitucional de municipalidades, Diario Oficial, 26 de julio de 2006;

Ley $\mathrm{N}^{\circ}$ 20.219, destina recursos para el fondo de desarrollo de la región de Magallanes y de la Antártica chilena y modifica otros cuerpos legales que indica, Diario Oficial, 3 de octubre de 2007; 
Decreto con Fuerza de Ley $\mathrm{N}^{\circ}$ 1, fija texto refundido, coordinado y sistematizado de la ley de tránsito, Diario Oficial, 29 de octubre de 2009;

\section{JURISPRUDENCIA CITADA}

Requerimiento de inconstitucionalidad respecto del DFL $N^{\circ} 1^{\circ}$ de 1971 (1972): Tribunal Constitucional, de 5 de abril de 1972, rol 5 [fecha de consulta: 20 de mayo de 2013]. Disponible en www.tribunalconstitucional.cl;

Control de constitucionalidad respecto del proyecto de ley orgánica constitucional sobre el Banco Central (1989): Tribunal Constitucional, de 20 de septiembre de 1989, rol 78 [fecha de consulta: 31 de mayo de 2013]. Disponible en www.tribunalconstitucional.cl;

Requerimiento respecto de la indicación $N^{o} 148$, de S. E. el Presidente de la República, en el proyecto de ley que introduce modificaciones a la Ley No 19.070, que Aprueba el Estatuto de los Profesionales de la Educación (1995): Tribunal Constitucional, 10 de julio de 1995, rol 217 y 218 (acumulados), [fecha de consulta: 28 de mayo de 2013]. Disponible en www.tribunalconstitucional.cl;

Control de constitucionalidad respecto del proyecto de ley que modifica el Decreto Ley $N^{o} 701$, de 1974, sobre Fomento Forestal (1998): Tribunal Constitucional, 31 de enero de 1998, rol 271 [fecha de consulta: 28 de mayo de 2013]. Disponible en www.tribunalconstitucional.cl;

Control de constitucionalidad respecto del proyecto de ley que concede beneficios económicos al personal del Servicio de Impuestos Internos, del Consejo de Defensa del Estado, de la Dirección de Presupuestos y de las Fuerzas Armadas, y contiene otras normas sobre racionalización del sector hacienda (1999): Tribunal Constitucional, 2 de noviembre de 1999, rol 297, [fecha de consulta: 28 de mayo de 2013]. Disponible en www.tribunalconstitucional.cl;

Requerimiento de inconstitucionalidad respecto del Decreto con Fuerza de Ley No 21, de 2003, del Ministerio de Hacienda (2003): Tribunal Constitucional, 11 de noviembre de 2003, rol 392, 393 y 394 (acumulados), [fecha de consulta: 20 de mayo de 2013]. Disponible en www.tribunalconstitucional.cl;

Izquierdo Artigas (2007): Tribunal Constitucional, 16 de enero de 2007, rol 626, requerimiento de inaplicabilidad [fecha de consulta: 20 de mayo de 2013]. Disponible en www.tribunalconstitucional.cl;

Requerimiento de inconstitucionalidad respecto del Decreto Supremo No 80, que "Establece la norma de emisión para molibdeno y sulfatos de efluentes descargados desde tranques de relaves al estero Carén" (2007): Tribunal Constitucional, 26 de abril de 2007, rol 577 [fecha de consulta: 28 de mayo de 2013]. Disponible en www.tribunalconstitucional.cl;

Brahm Moura (2007): Tribunal Constitucional, 12 de junio de 2007, rol 794, requerimiento de inaplicabilidad [fecha de consulta: 20 de mayo de 2013]. Disponible en www. tribunalconstitucional.cl;

Silva Martínez (2007): Tribunal Constitucional, 27 de septiembre de 2007, rol 781, requerimiento de inaplicabilidad [fecha de consulta: 20 de mayo de 2013]. Disponible en www.tribunalconstitucional.cl; 
Lovera Ayca (2008): Tribunal Constitucional, 9 de septiembre de 2008, rol 1214, requerimiento de inaplicabilidad [fecha de consulta: 20 de mayo de 2013]. Disponible en www.tribunalconstitucional.cl;

Municipalidad de Arauco (2009): Tribunal Constitucional, 17 de marzo de 2009, rol 1145 [fecha de consulta: 28 de mayo de 2013]. Disponible en www.tribunalconstitucional.cl;

Pronunciamiento de oficio sobre la inconstitucionalidad de algunas de las expresiones contenidas en el inciso primero del artículo 171 del Código Sanitario (2009): Tribunal Constitucional, de 25 de mayo de 2009, rol 1345, [fecha de consulta: 20 de mayo de 2013]. Disponible en www.tribunalconstitucional.cl;

Requerimiento de inconstitucionalidad respecto del texto integro del artículo 595 del Código Orgánico de Tribunales (2009), 29 de julio de 2009, rol 1254, [fecha de consulta: 20 de mayo de 2013]. Disponible en www.tribunalconstitucional.cl;

Proyecto que modifica la Ley No 17.997 Orgánica Constitucional del Tribunal Constitucional (2009): Tribunal Constitucional, 25 de agosto de 2009, rol 1288 [fecha de consulta: 20 de mayo de 2013]. Disponible en www.tribunalconstitucional.cl;

Agrícola Bauzá (2009): Tribunal Constitucional, 24 de septiembre de 2009, rol 1284, requerimiento de inaplicabilidad [fecha de consulta: 20 de mayo de 2013]. Disponible en www.tribunalconstitucional.cl;

Paúl Latorre (2010): Tribunal Constitucional, 4 de noviembre de 2010, rol 1399 y 1469 (acumulados), requerimiento de inaplicabilidad [fecha de consulta: 20 de mayo de 2013]. Disponible en www.tribunalconstitucional.cl;

Requerimiento de inconstitucionalidad respecto del Decreto Supremo $N^{\circ} 264$, que "Fija normas complementarias al Decreto No 136 de 14 de septiembre de 2009" (2011): Tribunal Constitucional, 12 de mayo de 2011, rol 1849 [fecha de consulta: 28 de mayo de 2013]. Disponible en www.tribunalconstitucional.cl;

Proceso de inconstitucionalidad iniciado de oficio por el Tribunal Constitucional en relación al artículo 2331 del Código Civil (2011): Tribunal Constitucional, 24 de mayo de 2011, rol 1723 [fecha de consulta: 28 de mayo de 2013]. Disponible en www.tribunalconstitucional.cl;

Requerimiento respecto de la constitucionalidad del Convenio Internacional para la Protección de Obtenciones Vegetales (UPOV-91): Tribunal Constitucional, 26 de junio de 2011, rol 1988 [fecha de consulta: 28 de mayo de 2013]. Disponible en www.tribunalconstitucional.cl;

Coloma Correa (2012): Tribunal Constitucional, 5 de junio de 2012, rol 1990, requerimiento de inaplicabilidad [fecha de consulta: 20 de mayo de 2013]. Disponible en www.tribunalconstitucional.cl;

Jordán Astaburuaga (2012): Tribunal Constitucional, 18 de diciembre de 2012, rol 2254, requerimiento de inaplicabilidad [fecha de consulta: 20 de mayo de 2013]. Disponible en www.tribunalconstitucional.cl;

Alvarado Andrade (2013). Tribunal Constitucional, 31 de enero de 2013, rol 2246 [fecha de consulta: 28 de mayo de 2013]. Disponible en www.tribunalconstitucional.cl;

BBVA (2013): Tribunal Constitucional, 2 de mayo de 2013, rol 2259, requerimiento de inaplicabilidad [fecha de consulta: 20 de mayo de 2013]. Disponible en www.tribunalconstitucional.cl; 
Contraloría General de la República, Dictamen N 47.681, de 23 de octubre de 2003 [fecha de consulta: 20 de mayo de 2013]. Disponible en www.contraloria.cl

Tribunal Constitucional español, sentencia 50/1984, de 5 de abril de 1984 [fecha de consulta: 20 de mayo de 2013]. Disponible en www.tribunalconstitucional.es 
